\title{
Cross-laboratory comparison of fluorimetric microplate and colorimetric bench-scale soil enzyme assays
}

Dick, Richard; Dick, Linda; Deng, Shiping ; Li, Xiufen ; Kandeler, Ellen ; Poll, Christian; Freeman, Christopher; Jones, Timothy; Weintraube, Michael N. ; Saxena, Jyotisna

\section{Soil Biology and Biochemistry}

Published: 01/06/2018

Peer reviewed version

Cyswllt i'r cyhoeddiad / Link to publication

Dyfyniad o'r fersiwn a gyhoeddwyd / Citation for published version (APA):

Dick, R., Dick, L., Deng, S., Li, X., Kandeler, E., Poll, C., Freeman, C., Jones, T., Weintraube, M. N., \& Saxena, J. (2018). Cross-laboratory comparison of fluorimetric microplate and colorimetric bench-scale soil enzyme assays. Soil Biology and Biochemistry, 121, 240-248.

\footnotetext{
Hawliau Cyffredinol / General rights

Copyright and moral rights for the publications made accessible in the public portal are retained by the authors and/or other copyright owners and it is a condition of accessing publications that users recognise and abide by the legal requirements associated with these rights.

- Users may download and print one copy of any publication from the public portal for the purpose of private study or research.

- You may not further distribute the material or use it for any profit-making activity or commercial gain

- You may freely distribute the URL identifying the publication in the public portal ?
}

Take down policy

If you believe that this document breaches copyright please contact us providing details, and we will remove access to the work immediately and investigate your claim. 


\title{
Manuscript Details
}

\section{Manuscript number}

Title
SBB_2016_49_R1

Cross-laboratory Comparison of Fluorimetric Microplate and Colorimetric Benchscale Soil Enzyme Assays

Research Paper

\begin{abstract}
There has been growing interest in fluorescence-based microplate methods to measure enzyme activities due to the sensitivity of fluorimetric detection and the potential for simultaneous and rapid assaying of multiple enzyme activities in the same soil suspension. However, micro-scale methods could introduce considerable operator error such as: 1) the requirement to put soil samples into a suspension; 2) the very small amounts of soil placed in each microplate well; 3 ) pipetting error because $\mu \mathrm{L}$ volumes are required; and 4) the need for standard curve calibration with every sample to account for quenching. For valid data comparison and interpretation, there is clearly a need to have a strict and agreed-upon enzyme assay protocol to standardize the microplate-based method. Therefore, the objectives were to: 1) determine the reproducibility and comparability of the standard p-nitrophenol bench-scale and 4methylumbelliferone microplate enzyme assays measured by five laboratories for $\beta$-glucosidase (EC 3.2.1.21) and acid phosphomonoesterase (EC 3.1.3.2) on the same soil samples; and 2) determine the degree and the sources of variability associated with the assays within and among the laboratories. The results showed that overall variability was highest for replication on the microplate $(n=4)$, whereas suspension replication had low CVs. This suggests an important source of variation is from pipetting not variability from soil suspensions. A major effort was made to control for methodological differences by using air-dried soils (therefore more stable over varying storage periods) and operator consistency for each task across the labs (e.g. preheated reagents, microplate reader sensitivity set to the highest standard, readings taken within an hour of reaction termination, and controls for substrate autohydrolysis). As a result, the differences among labs were much smaller than differences due to soil type for the microplate method, indicating operator error can be minimized by following the same strict protocol. At the molar level, enzyme activity rates measured across the five labs were not the same between bench and MUF microplate methods (although they were within an order of magnitude), but were quite similar in terms of ranking of soil management treatments and soil types (Table 2). Correlations between bench and microplate assays were strong for both enzymes, although slightly stronger for acid phosphomonoesterase $(r=0.93)$ than $\beta$-glucosidase $(r=0.81)$. Additionally, for both acid phosphomonoesterase and $\beta$-glucosidase, correlation $r$ values were mostly similar for MUF microplate and PNP bench method correlation with EL-FAME biomarkers, suggesting both methods were measuring activity originating from the same microbial groups. We conclude that different labs using the same MUF microplate protocol tested, gives reasonably similar absolute activity values, variability, and ranking of treatments (highest to lowest). We propose that the MUF microplate method described in this study be considered as a standard protocol for assaying soil enzyme activities, providing that the buffer $\mathrm{pH}$ for the incubation be adjusted to the optimal $\mathrm{pH}$ according to the enzyme of interest.
\end{abstract}

Keywords

Taxonomy

Manuscript region of origin

Corresponding Author

Order of Authors

Suggested reviewers cross-lab study; soil enzyme methods; microplate; 4-methylumbeliferone; $p$ nitrophenol

Soil Microbial Ecology, Enzymatic Methods

North America

Richard Dick

Richard Dick, Linda K. Dick, Shiping Deng, Xiufen Li, Ellen Kandeler, Christian Poll, Chris Freeman, Timothy Graham Jones, Michael Weintraub, Kawthar Esseili, Jyotisna Saxena

Tom Speir, Denis Angers, David Coleman 


\section{Submission Files Included in this PDF}

File Name [File Type]

Cover letter SBB Cross lab study.doc [Cover Letter]

Response Cross Lab Enzyme Study Reveiw Comments 4Oct17 (2).doc [Response to Reviewers]

Highlights.doc [Highlights]

Cross lab Enzyme Method Study Post Review Final 160ct17.docx [Manuscript File]

Figures.pdf [Figure]

Procedures MUF Cross Lab Study 24Sep17 Final After Review.doc [e-Component]

To view all the submission files, including those not included in the PDF, click on the manuscript title on your EVISE Homepage, then click 'Download zip file'. 


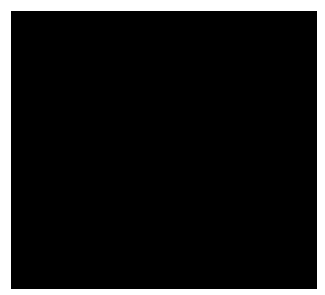

2021 Coffey Road Columbus $\mathrm{OH}$ Natural Resources $43210-1085$

Phone 614-2922265FAX 614292-74

29 September, 2016

Dear Editor:

We are submitting the manuscript entitled "Cross-laboratory Comparison of Fluorimetric Microplate and Colorimetric Bench-scale Soil Enzyme Assays" that has the following authors: Richard P. Dick, Linda K. Dick; Shiping Deng; Xiufen Li, Ellen Kandeler; Christian Poll; Christopher Freeman; Timothy Graham Jones; Michael N. Weintraub; Kawthar A. Esseili; and Jyotisna Saxena.

This is original research and it was presented at the International Conference - Enzymes in the Environment: Activity, Ecology, and Applications, 24-27 July, 2016, Bangor, Wales, UK.

Thank you

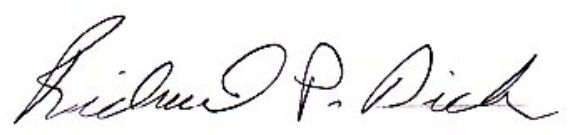

Professor 
Cross Lab Enzyme Study

Soil Biology and Biochemistry

\section{Reviewer 1}

1) I was enthusiastic about reading this manuscript and hoped to gain insights into variability and potential sources of error with the microplate approach. Unfortunately, rather than present a rationale and evidence-based argument that the method presented is the one to use, the manuscript contains many assertive statements (for example, that a strict method is needed), without good arguments for the case. The need for a strict, standardized method is repeatedly mentioned, but the experimental testing presented is at times vague on details, or variable between laboratories.

The comparisons performed are also somewhat bewildering: if part of the rationale was to compare small scale microplate methods to larger scale "bench top" methods, why use different artificial substrates for those comparisons (microplate MUF to benchtop pNP)? It's very possible that microbial enzymes could show different affinities for different substrate types, and that this could vary between samples. It seems that it would have been easy to run both MUF and pNP assays in both microplate and benchtop form.

\section{RESPONSE:}

1a) pNP microplate method is less sensitive and troublesome. According to Deng et al. (2013), in the presence of soil suspension, as little as 50 pmol of 4-methylumbelliferone, compared to $16.28 \mathrm{nmol}$ of $\mathrm{pNP}$, can be detected in each assay. Furthermore, soil particles in the wells interferes with absorbance reading, lead to considerable background readings and cause high variability in pNP microplate method. Fluorescence measurements are known to be significantly less susceptible to the effects of turbidity compared to absorption based detection (Deng et al. 2011). This suggests that MUF microplate is more desirable.

1b) MUF bench method is not needed because the pNP bench method offers sufficient sensitivity for its detection, adequate stability for the convenience in routine laboratory analysis, and relatively low cost to be feasible (MUF at bench scale is very expensive) and adaptable for most research programs.

1c) Thus the effort in this study was focused on MUF microplate method, which is now widely used but yet with limited understanding on its reliability and sources of variability. We compared microplate method to the bench method which, for both enzyme assays in our study, has been well vetted. So the goal here was very practical in moving towards standardizing a MUF microplate procedure that if followed would allow cross study comparisons and meta-analysis of soil enzyme activity data. We used as much information as possible from previous research on microplate methods and implemented a protocol that was guided by the groundwork of research on the bench scale method. 
1d) The employed bench method for the enzyme assays are vetted and standardized methods. The bench methods are based on sound chemistry/biochemistry principles that measures potential activity of enzymes in soils. We understand that it is very possible that an enzyme could show different affinities for different substrate types, and that this could vary between samples. In theory, the detected enzyme activity, however, should be comparable regardless of method of detection, providing that the methods are based on sound science and have been systematically evaluated. Our working hypothesis was that if both methods under different operators had statistically acceptable levels of variability, comparable absolute values (on molar basis), and consistent ranking of tested soil types, then we would conclude that the microplate method offers sufficient reproducibility as a reliable method for valid evaluation of soil enzyme activity. For meaningful comparison, variability and treatment ranking between methods are important, even if absolute values do not match up. This rationale is stated in the Introduction in the original submission (starting on L66).

2) Similarly, the number of replicates differs between the two methodological approaches. Why not standardize this?

RESPONSE: We assume that analytical replicates were implied in this comment. The required number of replicates in an assay is closely related to variability and reproducibility of an assay protocol. It is, therefore, method dependent. For the bench assays, duplicate assays were sufficient to offer statistically acceptable variability. These methods have been developed and systematically evaluated in M.A. Tabatabai's program, which have shown high precision (often $<5 \%$ coefficient of variance) with the vetted protocols. For the microplate method, a larger number of analytical replicates are required because higher variability was expected due to the high sensitivity of detection, quenching of fluorescence by the soil suspension, and small amount of sample employed in each assay (Freeman et al., 1995; Deng et al., 2013; Deng et al., 2017). Unfortunately, most MUF-based microplate assays in the literature did not include assay replicates of soil suspensions as discussed in Deng et al. (2017). The replicates of up to 16 microplate wells in each assay were originated from the same soil suspension, which would account for variability introduced by pipetting. Deng et al. (J. Microbiol. Meth. 133:32-34. 2013) showed that 4 replicated wells were sufficient to address variability introduced by pipetting. The number of assay replications used in this study was based on previous research reports.

3) The FAME assays also seem out of place. They're not addressed in the abstract and seem more like an afterthought or an extra set of data that was just added and not really examined thoroughly.

RESPONSE: The focus of this study was on methods comparison. However, FAME data provided additional data validation and more in-depth data interpretation and understanding. The reason for the FAME assays was stated in the original submission (now L321-24). 
"To give some insight into the relationship between the two enzyme activities assayed by bench and microplate methods and microbial community profiles, fatty acid methyl esters (EL-FAMEs) were used as biomarkers for major functional microbial groups. The biomass of each microbial group was correlated with enzyme activities (Table 7)."

We revised the abstract to reflect the effort.

4) Finally, I'd also question the need and timing of a manuscript like this. Microplate assays are hardly new - they've been around for $>20$ years - so presenting them as a new approach that needs to be standardized compared to "traditional" methods seems somewhat dated.

RESPONSE: This is an excellent question and we agree that this research could have been done years ago. The microplate assay protocols were guided by the groundwork on the bench scale method; but were not systematically evaluated as done for the bench assays (Tabatabai, 1994). Over time, challenges have emerged. This study was motivated to address unaddressed issues facing the assay, for validate data comparison and meaningful interpretation. In research, reliability of a method is of paramount importance and particularly prudent when a method is widely being used, but not standardized; regardless if the method is relatively new or old.

Specific points by line

5) 8-9 Is this statement really true? Is it necessary to have a strict and agreed-upon protocol for valid data comparison and interpretation? Maybe for some comparisons between studies, but otherwise no. And of course the authors would like it to be their "strict and agreed-upon protocol" - although they don't present any comparisons to different protocols, just their own.

RESPONSE: We are surprised by this comment that agreed-upon protocols are necessary because for any research endeavor this is fundamental science. A method does not belong to anyone, but is one that is widely accepted by the scientific community. The method must be based on sound science, ideally easy to perform, and reproducible. The latter requires systematic evaluations of the assay protocol, which for enzyme activity assays is the "Tabatabai protocol" (some referred to them as "classic methods"). The microplate method in our study is based on the evolution across these method development papers Marx et al., 2001; DeForest, J.L., 2009; German et al., 2011; Deng et al., 2011, 2013; Dick et al., 2013.

For a more detailed discussion of systematic method evaluation, please see: Dick, W.A. 2011. Development of a Soil Enzyme Reaction Assay. R.P. Dick (ed.) Methods of Soil Enzymology, SSSA Book Series. No. 9.. Soil Science Society of America, Madison, WI USA. dol:10.2136/sssabookser9.c14

6) 13-14 Sources/causes of variability aren't really addressed. Some speculation on the cause of variability but none were actually tested. 
RESPONSE: The paper is fully focused on sources of variability from the field down to the lab analytical replication - as shown in Tables 3-5 with standard errors shown in Table 2.

7) 25 Don't cite a Table in an abstract

RESPONSE: Deleted

8) 22, 26-27 References to the importance of following a strict, standardized protocol, but this wasn't actually tested. Would allowing each lab to have conducted assays according to their own protocols have led to, for example, the same ranking of soils?

RESPONSE: We did not test strict protocols - we all agreed to strictly follow the same protocols for the 2 methods compared in the study - here by strict we mean that we agreed all follow the exact same protocol.

9) 83 Spell out THAM on first use

RESPONSE: We respectfully disagree - this is a widely used and recognized abbreviation in the discipline. We recognize that in biology/molecular biology it is often referred to as "Tris").

10) 90-92 Is a quench standard curve necessary? Quench controls (MUF with sample) can also be used.

RESPONSE: Yes it is necessary

11) 98-102 The larger mass of soil used in benchtop assays is likely as big a factor (if not more) as pipetting error for more variability in microplate assays.

RESPONSE: Based on principles of analytical chemistry, the larger mass of soil used in bench assays would result in lowering variability and analytic errors from assay to assay.

12) 101-102 Why would variability in protocols exacerbate these methodological issues? Not clear

RESPONSE: We agree this was confusing as this was referring to lab to lab comparability and as such this statement was deleted.

13) 104-105 Again, why a strict and agreed-upon protocol? Who needs to agree (the limited number of authors?).

RESPONSE: Please see response to question \#5 above.

14) 130 How was soil homogenized? 
RESPONSE: L133 - Rewritten to clarify.

15) 131 (and elsewhere) I'm not convinced that air drying is a valid method for preservation. This allows all sorts of microbial processes to take place and in my experience is not a substitute for running fresh assays, regardless of the protocol used (MUF vs. pNP, microplate vs. bench). This would not be an acceptable method for other microbial assays (e.g. community composition) and it's bewildering why we think it is for a physiological measure. Why not at least freeze dry? Even if acceptable, no details on air drying (temperature, humidity, time) are presented.

RESPONSE: This was done to stabilize the sample and reduce variability because soil had to be shipped long distances and leaving them field moist would undoubtedly resulted in more variability. This was confirmed by the obtained results which showed that even though the time between soil sampling/processing and analysis, varied considerably across labs - the results were quite consistent. We agree that field fresh samples is needed when the study objective is focused on microbial analyses related to viable cells. However, decades of research have demonstrated that activities of soil enzymes are originated mostly from cell-free stabilized extracellular enzymes (Tabatabai, 1994). Enzyme activities in soil indicate a biochemical property of a soil, not necessarily correlated with microbial activities. Based on evaluation of $20+$ soils under various conditions, Frankenberger and Dick (1983. SSSAJ 47:945-951) found that enzyme activities and microbial activities in soil were significantly correlated only when sugar was added to the soil prior to the test. Furthermore, for the enzymes used in this study research data have shown that the activity for a given enzyme may go down some with air drying, the relative ranking of treatments or across soil types stays the same (e.g. phosphatase - Eivazi and Tabatabai, 1977; beta-glucosidase - Eivazi \& Tabatabai, SBB 22:891; Bandick and Dick, 1999).

16) 167-168 "within two weeks of receiving..." is vague and variable. Why not follow a "strict" timeline? And the data from one laboratory that took "within four weeks" (presumably really 2-4 weeks) should be excluded.

RESPONSE: It was the best we could do given that 2 of the participating labs were in Europe. Again despite this variation in time to analysis, the results were quite consistent as expected.

17) 172-173 Why even include Lab 5 if they weren't doing the whole process? This, and the prior comment, just highlight how poorly standardized this experiment was.

RESPONSE: This lab was not set up to do the bench method, but has extensive experience in the microplate method. Including lab 5 strengthened data interpretation to further confirm or refute the study hypothesis that operator error was minimal in using the microplate method and gave 5 instead of 4 reps to determine microplate variability. 
18) 178 Why $37 \mathrm{C}$ ? What is the rationale for conducting assays of environmental enzymes at human body temperature? Combine a non-realistic temperature with a non-realistic $\mathrm{pH}$ and we're getting quite far removed from environmental conditions.

RESPONSE: See response to \#15. An enzyme is very different than a viable cell and as such optimizing for $\mathrm{pH}$ and temperature to measure activity as an index of the isoenzymes present in the soil is fundamental biochemistry. In this study, potential enzyme activities in soil were measured. The study objective was not to evaluate "in situ" enzyme activities in soil. The choice of temperature and $\mathrm{pH}$ for the assay followed those used in the well accepted bench methods (i.e. Tabatabai, 1994). Yes, human body temperature was selected to be used. Enzyme activities increases with increasing temperature with a Q10 value often exceeding 2. The assaying temperature of $37^{\circ} \mathrm{C}$ allows sensitive detection of most soil enzymes, but does not raise concern on enzyme denaturation which occurs around $60-65^{\circ} \mathrm{C}$ in soil. An enzyme assay is an index of the amount of isoenzymes that is in the soil sample that can perform a given reaction - for sensitivity and comparability, it is best to conduct the assay under optimized conditions. As soon as non-optimized conditions are not used, activity goes down and no longer is the assay truly able to be an index for the total amount of isoenzymes that are present. This could very well obscure treatment effects or even show non-significant differences when if they had been done under optimal conditions there would have been differences.

19) 180 -181 Is using a stir bar and plate really "homogenizing" rather than just mixing?

RESPONSE: This is a matter of semantics - According to Webster: Homogenize: "to make uniform in structure or composition throughout" Mix: "to combine or blend into one mass"

20) 184-185 What are the substrates dissolved in?

RESPONSE: Water

21) 186 "several times" is vague; covered with what?

RESPONSE: 2-3 times, revised.

22) 191-193 Need more information on models of microplate readers and sensitivity settings. This is a major source of variability and it's glossed over.

RESPONSE: We disagree because if the sensitivity (gain) settings are based on the highest calibration standard (which all labs did), the results are normalized. All labs got comparable results would confirm this.

23) 194-198 This section on controls is vague. Does not adding substrate initially mean that a $0 \mathrm{M}$ substrate solution was used (to keep volumes standardized) or that nothing was added (so volumes of controls were less than that of reactions)? 
RESPONSE: Yes, the volume in the controls were less than that of the assayed sample during incubation. The substrate was added to the control following incubation and termination of the reaction. Detailed description can be found in the paper and/or the supplementary information.

24) 199-200 Again, varying reagents is yet another source of variation that should have been standardized for a "strict" protocol. These could have been shipped along with the soil samples.

RESPONSE: All substrates were the exact same compounds. Moreover, controls employed in the assay should have accounted for any potential variations in substrate auto-hydrolysis from variations in source and/or storage.

25) 211 Why 37 C?

RESPONSE: See above response to \#18.

26) 216-218 As with the MUF assays, it's not clear if an equal volume of $0 \mathrm{M}$ substrate was used for controls or no additional volume.

RESPONSE: See response to \#23. Controls and sample assays had the same volumes when taking the measurements.

27) 218 What instrument was used for absorbance measurements?

RESPONSE: Spectrophotometer

28) 227-228 Why not a 2-way ANOVA to allow for the detection of lab x sample interactions? Shouldn't the follow-up tests (multiple pairwise comparisons) need something like the Bonnferonni correction?

RESPONSE: 2-Way ANOVA was done and added to the $\mathrm{M} \& \mathrm{M}$. We ran the Bonferoni test and got the same outcome.

29) 243-248 Seems off topic

RESPONSE: This puts the methods' results in the context of the field treatments which in the next paragraph these soil properties are linked with the enzyme methods.

30) $277-278$ As mentioned earlier, it would be reasonable to expect different affinities of different enzymes for $\mathrm{pNP}$ or MUF substrates

RESPONSE: We agree that this could be a factor. We added this on L291: "Although there is greater affinity by MUF over PNP (as shown by Km values presented by Marx et al, 2001 and Deng et al., 2013) which could change the activity rate, it should be a 
consistent effect. A more likely factor contributing to variability detected by the MUF method is quenching of the emitted fluorescence by soil particles."

31) 294-295 Speculation. No evidence is presented that different times between sampling had no effect

RESPONSE: We have recently shown that for B-glucosidase air dried soil kept at room temperature, $4 \mathrm{C}$ or $-20 \mathrm{C}$ was stable on the order of months. This was added on L310.

32) 298-299 Didn't alter "ranking" is not the same as didn't alter activity

RESPONSE: We agree and this statement does not contradict that.

33) 300-302 Vague. Nothing in this study validates the use of air-dried samples

RESPONSE: These statements are not validating air drying over field moisture nor advocating one over the other - just making a comment enzyme assays can be run on airdried samples. See REPSONE 39.

34) 317-328 The emphasis on FAME here seems out of order (presenting info in Table 7 ahead of Tables 3 and 4)

RESPONSE: This section was moved to the Bench vs. Microplate section (L321).

35) 360-363 Why not vary the mass of soil to see if this actually is a major factor?

RESPONSE: This was discussed based on principles in analytical chemistry. For the PNP bench method, sample size has been well tested and established. Reducing soil mass to the same level employed in the microplate methods is not possible. First, the enzyme activity would not be detectable because PNP is not as sensitive as MUF. Second, this would require development of a new assay protocol, which is beyond the scope of this paper. On the other hand, increasing soil mass in the MUF microplate method to that of the PNP bench method is not possible as well. In the microplate assay methods, soil suspensions are used in the assay. Pipetting mud into microplate wells is challenging. This change would also require systematic evaluation of the protocol, which again is beyond scope of the study. Moreover, studies of the MUF microplate method where substrate concentration curves were developed - the standard MUF substrate concentration is in excess - meaning the enzymes were saturated. This indicates the $1 \mathrm{~g}$ of soil put in to suspension when distributed to plate wells was not in excess to cause unsaturated substrate conditions.

36) 414-417 While my own assays do tend to use a standard $\mathrm{pH}$, the argument that varying $\mathrm{pH}$ based on sample $\mathrm{pH}$ prevents direct comparisons isn't a good one. One could just as easily argue that not adjusting $\mathrm{pH}$ to the in situ $\mathrm{pH}$ of the soil prevents valid comparisons of actual real world activity, and at best gives just an estimate of potential 
activity (under standardized conditions of $\mathrm{pH}$ and temperature that may have no real world application).

RESPONSE: This would be objective dependent. The objective of this study was to determined potential enzyme activities in soil. See responses to \#18 above. Moreover, it is challenging to determine actual "in situ" soil enzyme activity in the laboratory, as the soil would be removed from the field and processed, and the assay conditions are totally different from the in situ environment.

37) 421-442 I don't follow why a 1 hour lag between reaction termination and reading was even necessary. Terminate the reaction, read the plate: 2 minute lag time, max.

RESPONSE: This is just to indicate the amount of time available in case for what ever reason there is variability in the time between terminating the reaction and reading fluorescence for a given operator. Deng et al. (2013) showed that there was very little changes in fluorescence within $3 \mathrm{hrs}$ following termination with THAM (Fig. 1, Deng et al., 2013).

38) 426-428 The major problem here is that only one method is presented or tested, but then is proposed to be the standard method. No alternative methods were evaluated.

RESPONSE: Many methods in soil analyses have components that are operationally defined in order to allow results to be comparable from study to study. The microplate method we are proposing is based in part on the vetted bench method for the 2 enzymes in the study (Tabatabai, 1994) and on microplate studies (Freeman et al.,1995; Marx et al., 2001; Drouilon and Merckx, 2005; Deng et al, 2013, Dick et al., 2013). For an enzyme assay the criteria is straight forward: substrate is in excess, co-factors present (when needed), long enough incubation for adequate product detection, high enough temperature to minimize incubation time, adequate enzyme concentration (amount of soil), and optimum $\mathrm{pH}$. So developing a soil enzyme assay is not done in comparison to alternative methods but rather establishing agreed upon operationally defined components and optimization.

\section{Reviewer 2}

39) This is a well-written, interesting article that highlights potential sources of variation in assaying for soil enzymes using colorimetric and fluorimetric approaches. My major concern is that while the recommended protocols will likely reduce the variability among labs, will they still capture the biologically relative variation found within field conditions? Using air-dry and incubating at unnaturally warm temperatures seems like a biological filter that would reduce the natural variation found within a soil sample. While this approach has been used for decades, it doesn't necessary mean it is the best approach at all research questions. For example, drying soil will significantly reduce the activity of phosphatase (Sparling et al., 1986, SBB), although results can be mixed (Zornoza et al., 2006, SBB). 
RESPONSE: Decades of research have demonstrated that activities of soil enzymes are originated mostly from cell-free stabilized extracellular enzymes (Tabatabai, 1994). Enzyme activities in soil indicate biochemical property of a soil, not necessarily correlated with microbial activities. Based on evaluation of $20+$ soils under various conditions, Frankenberger and Dick (1983. SSSAJ 47:945-951) found that enzyme activities and microbial activities in soil were significantly correlated only when sugar was added to the soil prior to incubation and testing. Field-moist fresh soil samples are needed when the study objective is focused on microbial analyses related to viable cells. We are not advocating for or against air drying. Air-drying was done to stabilize the sample and reduce variability because soil had to be shipped long distances and leaving them field moist would undoubtedly resulted in more variability. Yes, air-drying would result in lower enzyme activity, but should not affect relative comparison of the samples. This was confirmed by the obtained results which showed that even though the time between soil sampling/processing and analysis, varied considerably across labs - the results were quite consistent across labs. Furthermore, for the enzymes used in this study - research data have shown that the activity for a given enzyme may go down some with air drying, but the relative ranking of treatments or across soil types stays the same (e.g. phosphatase - Eivazi and Tabatabai, 1977; beta-glucosidase - Eivazi \& Tabatabai, SBB 22:891; Bandick and Dick, 1999)

40) This is the crux of these types of enzyme papers: Do you standardize to ensure repeatability among labs or do we optimize to best represent in-situ conditions? There is no 'right' answer to this question, but there clearly are researcher firmly in each camp. Regardless, I think this article should provide the potential down-side of strict standardization. For example, is a 1 hour incubation time at $37^{\circ} \mathrm{C}$ useful for all soils (e.g. Arctic/cold soils or ones with very low activity)? Likewise, consider in your recommendations that authors make it obvious in their methods section that they should report if methods were either optimized to standardized among lab or to optimize in-situ conditions.

RESPONSE: This is a reasonable question. Repeatability is important for any method. We think you meant optimized potential enzyme activity vs. in-situ enzyme activity. Method selection is objective dependent. If one were incubating and measuring viable microbial properties in situ conditions makes sense but an enzyme activity assay is straight biochemistry. In this study, potential enzyme activities were of interest and were measured. Some of the fundamentals are discussed in the response to \#43. The length of incubation time should not affect the determined enzyme activity because activities are often expressed as the amount of product released per unit time by unit of soil, providing that substrate is not limited during the incubation period. Incubation temperature, on the other hand, is an important factor affecting the measured enzyme activity. Enzyme activities increases with increasing temperature with a Q10 value often exceeding 2. Therefore, enzyme activities are comparable only when quantified at the same incubation temperature. For Arctic/cold soils or ones with very low activity, one can simply extend incubation time for the activities to be detectable (extending incubation time should not alter outcome of the measurement - activities determined). The commonly used assaying 
temperature of $37^{\circ} \mathrm{C}$ allows sensitive detection of most soil enzymes, but does not raise concern on enzyme denaturation which occurs around $60-65^{\circ} \mathrm{C}$ in soil.

41) I think the whole issue of pipette seems odd and only seems an issue unless manual pipette were used. It's unclear in this paper if the authors used a manual or an electronic pipette.

RESPONSE: We used electronic pipettes - but putting uL levels of a soil suspension is still of concern because a typical value of the soil in each well was only $0.83 \mathrm{mg}$. Clogging and air bubble problems are much more likely when working at $\mathrm{uL}$ suspensions compared to larger volumes of solutions.

Specific Comments:

42) Line 29 Where in this study is the evidence for this statement? This seems at odds with the idea of standardization, unless there is an internationally recognized accepted resource on $\mathrm{pH}$ optimal for these enzymes. If so, provide a reference.

RESPONSE: The recognized $\mathrm{pH}$ optima is based the extensive work of M. A. Tabatabai (Tabatabai, 1994). However, if there has not been $\mathrm{pH}$ curves developed for a given enzyme assay, then this needs to be determined before the assay is used as a research tool. We have acknowledged this and added text to this effect in L438-442 and L457 in the manuscript.

43) 104 I don't agree entirely with this statement and it seems too draconian. We can still have valid comparison and interpretation using a proper approach. While some information would be lost, using enzymes stoichiometry will allow researcher to compare even if their methods are different that likely influence the absolute activity.

RESPONSE: We do not view this as draconian and stand by this statement. The concern is that the further the procedure is from optimal temperature or $\mathrm{pH}$, the lower the activity which could mask treatment effects. Examples of this can be seen in some enzyme activity methods papers where on the extremes of the $\mathrm{pH}$ curve - soil types that are very different at the optimum $\mathrm{pH}$ then converge to levels that are very similar at very high or low $\mathrm{pH}$. So in effect the results are confounded by less than optimal conditions (e.g. if one is comparing soils where some have a natural $\mathrm{pH}$ near the optimum and others are not close to the optimum and then the $\mathrm{pH}$ is not buffered - those soils not at the optimum are going to be lower automatically which confounds the goal of enzyme assays as an index of the total amount of enzyme present). Furthermore, soil is known to be heterogeneous. Micro-habitats in soil could have markedly different $\mathrm{pH}$ values than the bulk soil, making it challenging to truly measure "in-situ" soil enzyme activities.

44) 259 What is meant by 'relative ranking'? This is not described in the methods section and it seems a considerable part of the comparison is based on this ranking approach. Please add some justification on how ranking is an appropriate approach to 
compare the two methods. Maybe a comparison of the ratio between these enzymes may be a better approach in comparison.

RESPONSE: Relative ranking referred to relative enzyme activities among the tested soils. Consistent ranking by different methods validates their use in detecting treatment effects (e.g. soil type or various soil management treatments).

45) 262 The approach for this analysis was not described in the data analysis section. Please provide the details.

RESPONSE: This has been added to the $\mathrm{M} \& \mathrm{M}$.

46)317 I like this approach of compared enzyme activities on something standard, like microbial biomass or soil $\mathrm{C}$. The authors clearly show that microbial biomass is strongly correlated with enzyme activity.

RESPONSE: Thank you.

47) 342 Is this a mistake? Sandy soils are the easiest to homogenize and dispense - Do you mean to stay in suspension?

RESPONSE: Rewritten to indicate that to keep in solution is a major concern.

48) 385 Please remove the extra ','

RESPONSE: Done

49) Tables 3-5 I don't find this tables very useful, I think they would be better placed in supplementary content.

RESPONSE: We respectfully disagree as these tables along with Table 2 are the heart of the paper. Tables 3-5 show the levels of variability at each stage for the bench and microplate methods. We acknowledge that they are complex, struggled how best to present this but in the end found this to be the most appropriate to support objectives of the study. 
Bench and microplate enzyme activities were similar and highly correlated;

Following strict enzyme protocols across labs yielded similar activities;

Microplate method had highest variability for plate pipetting and not soil suspension;

MUF microplate and bench methods across labs gave similar ranking of treatments;

A standard microplate enzyme method is recommended to enable cross-study

comparisons; 
Cross-laboratory Comparison of Fluorimetric Microplate and Colorimetric Bench-scale Soil

Enzyme Assays

Richard P. Dick ${ }^{1 *}$, Linda K. Dick ${ }^{1 ;}$ Shiping Deng ${ }^{2}$; Xiufen Li $^{2}$, Ellen Kandeler ${ }^{3}$; Christian Poll3;

Christopher Freeman ${ }^{4}$; Timothy Graham Jones ${ }^{4}$; Michael N. Weintraub ${ }^{5}$; Kawthar A. Esseili5; and

Jyotisna Saxena ${ }^{1}$

${ }^{1}$ School of Environment and Natural Resources, The Ohio State University, Columbus OH, 43210, USA; ${ }^{2}$ Department of Plant and Soil Sciences, Oklahoma State University, Stillwater, OK 74078, USA; ${ }^{3}$ Institute of Soil Science and Land Evaluation, University of Hohenheim, Stuttgart D-70593, Germany; ${ }^{4}$ School of Biological Sciences, Bangor University, Bangor, United Kingdom;

${ }^{5}$ Department of Environmental Sciences, University of Toledo, Toledo, OH, 43606, USA.

*Corresponding author:

.Phone: 614-247-7605, Fax: 614-247-6901; Email: dick.78@osu.edu 


\section{Abstract}

2 There has been growing interest in fluorescence-based microplate methods to measure enzyme

3 activities due to the sensitivity of fluorimetric detection and the potential for simultaneous and rapid

4 assaying of multiple enzyme activities in the same soil suspension. However, micro-scale methods

5 could introduce considerable operator error such as: 1) the requirement to put soil samples into a

6 suspension; 2) the very small amounts of soil placed in each microplate well; 3) pipetting error

7 because $\mu \mathrm{L}$ volumes are required; and 4) the need for standard curve calibration with every sample

8 to account for quenching. For valid data comparison and interpretation, there is clearly a need to

9 have a strict and agreed-upon enzyme assay protocol to standardize the microplate-based method.

10 Therefore, the objectives were to: 1) determine the reproducibility and comparability of the standard

$11 p$-nitrophenol bench-scale and 4-methylumbelliferone microplate enzyme assays measured by five

12 laboratories for $\beta$-glucosidase (EC 3.2.1.21) and acid phosphomonoesterase (EC 3.1.3.2) on the

13 same soil samples; and 2) determine the degree and the sources of variability associated with the

14 assays within and among the laboratories. The results showed that overall variability was highest for

15 replication on the microplate $(n=4)$, whereas suspension replication had low CVs. This suggests an

16 important source of variation is from pipetting not variability from soil suspensions. A major effort

17 was made to control for methodological differences by using air-dried soils (therefore more stable

18 over varying storage periods) and operator consistency for each task across the labs (e.g. preheated

19 reagents, microplate reader sensitivity set to the highest standard, readings taken within an hour of

20 reaction termination, and controls for substrate autohydrolysis). As a result, the differences among

21 labs were much smaller than differences due to soil type for the microplate method, indicating

22 operator error can be minimized by following the same strict protocol. At the molar level, enzyme

23 activity rates measured across the five labs were not the same between bench and MUF microplate 
24 methods (although they were within an order of magnitude), but were quite similar in terms of

25 ranking of soil management treatments and soil types (Table 2). Correlations between bench and

26 microplate assays were strong for both enzymes, although slightly stronger for acid

27 phosphomonoesterase $(\mathrm{r}=0.93)$ than $\beta$-glucosidase $(\mathrm{r}=0.81)$. Additionally, for both acid

28 phosphomonoesterase and $\beta$-glucosidase, correlation $r$ values were mostly similar for MUF

29 microplate and PNP bench method correlation with EL-FAME biomarkers, suggesting both

30 methods were measuring activity originating from the same microbial groups. We conclude that

31 different labs using the same MUF microplate protocol tested, gives reasonably similar absolute

32 activity values, variability, and ranking of treatments (highest to lowest). We propose that the MUF

33 microplate method described in this study be considered as a standard protocol for assaying soil

34 enzyme activities, providing that the buffer $\mathrm{pH}$ for the incubation be adjusted to the optimal $\mathrm{pH}$

35 according to the enzyme of interest.

Keywords: cross-lab study; soil enzyme methods; microplate; 4-methylumbeliferone; $p$-nitrophenol 


\section{Introduction}

53 Soil enzyme assays have traditionally been performed at the bench scale using spectroscopic

54 methods. There has been growing interest in fluorescence-based microplate methods to measure

55 enzyme activities because fluorimetric detection is sensitive, and the microplate format has potential

56 for simultaneous and rapid assaying of multiple enzyme activities from the same soil suspension. In

57 contrast, bench-scale methodology has lower throughput and sensitivity. Microplate-format enzyme

58 protocols have already been incorporated in many research laboratories; however, the lack of a

59 standardized method for performing the assays and the potential for methodological problems

60 (German et al. 2011) limits their usefulness for cross-study data comparisons and meaningful data

61 interpretation. Several validation steps are recommended prior to standardization and widespread

62 adaptation of new microbiological methods (AOAC, 2006; FEM, 2009; Green, 1996). Preliminary

63 validation involves establishing performance characteristics such as specificity, sensitivity,

64 reproducibility, and accuracy based on comparative testing with a reference method. Additionally, a

65 collaborative study may be done to compare the assay's performance across laboratories.

66 Evaluative studies of various fluorimetric microplate assays using 4-methylumbelliferone

67 (MUF) based substrates have been done in several laboratories (Deng et al., 2013; Drouillon and

68 Merckx, 2005; Marx et al., 2001; Pritsch et al., 2004; Trap et al., 2012), and most were done in the

69 same laboratories that developed the methods. However, the resulting data have not consistently had

70 the same outcomes between the fluorescent microplate and the colorimetric $p$-nitrophenol (PNP) 
71 bench-scale methods (Dick et al., 2013; Marx et al., 2001). Therefore, further cross-comparison

72 between these methods is required to determine the sources of variation.

73 Methodological discrepancies may account for some differences in assay performance.

74 Notable in the above studies were the different $\mathrm{pHs}$ under which the assays were performed. In

75 some, the buffer $\mathrm{pH}$ was adjusted to the $\mathrm{pH}$ of the soil (Drouillon and Merckx, 2005; German et al.,

76 2011; Trap et al., 2012), and in others, to the optimal pH for the enzyme (DeForest, 2009; Deng et

77 al., 2013; Dick et al., 2013; Marx et al., 2001).

78 It has long been established that MUF fluorescence intensity is $\mathrm{pH}$ dependent, with the

79 highest fluorescence signal around $\mathrm{pH} 10$. Moreover, when $\mathrm{NaOH}$ is used to increase MUF

80 fluorescence at the end of a fluorimetric enzyme assay, MUF fluorescence signal decreases over

81 time after $\mathrm{NaOH}$ addition, making it challenging for obtaining quantitative fluorescence readings

82 and for valid data comparison (DeForest, 2009; Drouillon and Merckx, 2005). German et al. (2011)

83 found $\mathrm{NaOH}$ addition to be a significant source of variation and recommended against the $\mathrm{NaOH}$

84 addition for samples at $\mathrm{pH} 4.5$ and higher, as they had no difficulty detecting the accumulation of

85 MUF over time at $\mathrm{pH} \geq 4.5$, even without increasing the sensitivity setting on their microplate

86 fluorimeter. THAM pH 10-12 is the optimal solution to add after the enzyme assay because the

87 fluorescence intensity highest due to the high $\mathrm{pH}$ and the signal remains stable up to three hours

88 because of the THAM buffer (Deng et al., 2013).

89 One advantage of fluorimetric over colorimetric microplate methods is that fluorescence,

90 unlike absorbance, is not increased by the presence of soil particles (Deng et al., 2013). However,

91 fluorescence chemistry presents its own complexities because of quenching effects and the potential

92 for chemical hydrolysis; both influence reproducibility. The quenching effect, due primarily to the

93 presence of soil particles and dissolved organic matter in the assay mixtures, has been shown to 
94 vary temporally and spatially (Freeman et al., 1995), and thus requires a calibration curve be

95 developed for every sample assayed.

96 Thus, microplate enzyme assay methods introduce several sources of variation that have the

97 potential to substantially affect assay reproducibility, and require careful execution of certain steps

98 by the operator to minimize the variation. In part, this is due to the very small amounts of soil that

99 must be used ( $0.83 \mu \mathrm{g}$ in a $250 \mu 1$ reaction volume in the current study) to minimize the quenching

100 effect and to accommodate the small-volume microplate wells. Furthermore, dispensing $\mu \mathrm{L}$

101 volumes of soil/buffer slurry with a pipette results in wide variations in the amount of soil added to

102 each assay well. Because of this, the analytical error intrinsic to microplate enzyme assays is

103 expected to be considerably larger than that of the conventional bench method. To minimize error,

104 more replication is required compared to traditional bench-scale methods.

105 Thus, there are legitimate concerns about reproducibility and whether different labs can

106 obtain comparable data from of the same samples. For valid data comparison and interpretation,

107 there is clearly a need to have a strict and agreed-upon enzyme assay protocol to standardize the

108 microplate-based method where different operators who follow these procedures obtain the same

109 results. This is not case for the MUF microplate method as there has been considerable variation in

110 the protocols used in the literature. Therefore, a cross-lab study was done on an optimized MUF

111 procedure that has evolved from a number of labs (Marx et al., 2001; DeForest, J.L., 2009; German

112 et al., 2011; Deng et al., 2011, 2013; Dick et al., 2013)

113 Since PNP bench-scale enzymes assays are widely used, largely vetted for standardization,

114 and accepted, the objectives of this study were to determine the reproducibility by different

115 laboratories for assaying activity of $\beta$-glucosidase (EC 3.2.1.21) and acid phosphomonoesterase (EC

116 3.1.3.2) in the same soil samples using MUF microplate methods in comparison with standard PNP 
117 bench-scale assays; and to determine the degree and the sources of variability associated with these

118 two assays within and among five laboratories.

\section{Materials and Methods}

\section{Soils, sampling and storage}

The four soils selected were: 1) a sandy soil from the Ottokee fine sand series (sandy, mixed, 123 mesic Aquic Udipsamments) under soybean (Glycine max) near Napoleon, Ohio (OTB); 2) a soil

124 with higher clay content from the Miamian silt loam series (fine, mixed, active, mesic Oxyaquic 125 Hapludalfs) under mixed grasses at the Ohio State University Waterman Farm, Columbus, Ohio 126 (MMN); 3) a Jory silty clay loam (fine, mixed, active, mesic Xeric Palehumults) under Christmas 127 tree (Pseudotsuga menziesii at time of sampling) management (32 yrs) and vegetation-free except 128 for the trees, near Corvallis, Oregon (JMN); and 4) a Jory silty clay loam under $>90$ yrs unmanaged 129 Douglas Fir (Pseudotsuga menziessi) forest (JOG). The two Jory soil sites are side by side. Approximately $3 \mathrm{~kg}$ of soil were collected at each sampling site along a transect at three 131 spatially separated points (field replications) approximately $50 \mathrm{~m}$ apart. At each sampling site a $2 \mathrm{~m}$ 132 diameter area was sampled by taking about $300-15 \mathrm{~cm}$ depth cores with a probe (2.54 $\mathrm{cm}$ dia.).

133 Field moist soils were passed through a $2 \mathrm{~mm}$ sieve, which resulted in a thoroughly homogenized

134 sample. A large portion was air-dried; while a small portion was left field-moist. Air drying was 135 done by spreading soil on butcher block paper, spread at about $0.5 \mathrm{~cm}$ thick for 24 hours. The air136 dried soils were separated into $500 \mathrm{~g}$ samples and placed in sealed zip lock bags for shipment on ice

137 in Styrofoam containers to the collaborating laboratories. The field level replication was maintained 138 throughout the research, with each laboratory receiving three separate replicates of each soil, for a 139 total of 12 soil samples. The field-moist samples were either stored at $4^{\circ} \mathrm{C}$ for $\mathrm{pH}$ and soil texture 
140 analyses, or stored at $-20^{\circ} \mathrm{C}$ for Ester-Linked Fatty Acid Methyl Ester (EL FAME) analysis as an

141 index microbial community composition.

142 Soil chemical and biological properties

143 Total $\mathrm{C}$ and $\mathrm{N}$ contents were measured by dry combustion $\left(950^{\circ} \mathrm{C}\right)$ with a Vario Max $\mathrm{CN}$

144 Analyzer (Elementar; Hanau, Germany). Particle size distribution was determined by the pipette

145 method (Kilmer and Alexander, 1949), and soil $\mathrm{pH}$ was determined using a 1:1 soil/water (v/v) ratio.

146 Soil moisture content was measured by drying samples for $24 \mathrm{~h}$ at $105^{\circ} \mathrm{C}$. Chemical and physical

147 properties of the four soils used in the study are shown in Table 1.

148 The EL-FAME procedure was followed as described by Schutter and Dick (2000). In brief,

149 soil samples ( $3 \mathrm{~g}$ wet weight) were extracted with $0.2 \mathrm{M} \mathrm{KOH}$ in methanol, then incubated for $1 \mathrm{~h}$ at

$15037^{\circ} \mathrm{C}$ with periodic vortexing followed by solution neutralization of the $\mathrm{pH}$ with $1.0 \mathrm{M}$ acetic acid.

151 Extracted FAMEs were partitioned into an organic phase with hexane and centrifuged for 20 min at

$152500 \times g$ to with and then the separated hexane phase with EL-FAMES was dried under a stream of

$153 \mathrm{~N}_{2}$. FAMEs were resuspended in a known volume of hexane. FAME composition in the extracts

154 were determined using GC (Agilent 6890, Agilent Inc., Wilmington, DE) equipped with a 25-m HP

155 Ultra-2 column (internal diameter, $0.2 \mathrm{~mm}$; film thickness, $0.33 \mu \mathrm{m}$ ) and a flame ionization detector.

156 The temperature program ramped from 170 to $280{ }^{\circ} \mathrm{C}$ at $4{ }^{\circ} \mathrm{C}$ per min, with 5 min at $280{ }^{\circ} \mathrm{C}$

157 between samples to clean the column. Individual fatty acids were identified relative to several

158 standards: 37 FAMEs mixture (FAME 37 47885-4; Supelco, Inc), 24 bacterial FAMEs mixture (P-

159 BAME 24 47080-U; Supelco, Inc.), and MIDI standards (Microbial ID, Inc.). Quantification of

160 FAMES was accomplished by using varying concentrations of tridecanoic FAME (Supelco, Inc.)

161 and allowed peak areas to be converted to a molar basis (correlations with enzyme activities were

162 done on EL-FAMEs on a per nmol basis). Fatty acids comprising less than $0.5 \%$ of the total 
163 relative abundance were not included in the data analysis. Sums of the fatty acids indicative of

164 Gram-positive bacteria (GM+), Gram-negative bacteria (GM-), actinomycetes (actinos), plus the

165 five additional fatty acids listed are used as a measure of total bacterial biomass (Frostegard and

166 Bååth, 1996)

167 Enzyme assays

168 Two microplate enzyme assays using fluorescent methylumbelliferyl substrates, and two

169 bench-scale assays using chromogenic $p$-nitrophenyl substrates were compared across five

170 laboratories, each using identical protocols to measure $\beta$-glucosidase (EC 3.2.1.21) and acid

171 phosphomonoesterase (EC 3.1.3.2) activities in each of the 12 soil samples. The enzyme assays

172 were completed within two weeks of receiving the samples, with the exception of the bench-scale

173 assay in one laboratory that was completed within four weeks.

174 The five laboratories are located in three countries across two continents. All participating

175 laboratories had experience using fluorescence-based microplate methods. Labs 1 and 2 had

176 experience with the protocol used in the current study, which was developed in Lab 2. Lab 5 did not

177 have experience with the PNP bench-scale assay, and did not perform it in this study.

178 MUF Microplate Enzyme Assay

179 The MUF assay was done as described by Deng et al. (2011) with minor modifications.

180 Microplate layouts in the assay are shown in Figure 1, and were followed by all participating

181 laboratories. See supplemental section for detailed description of the method.

182 All reagents were brought to incubation temperature $\left(37^{\circ} \mathrm{C}\right)$ prior to beginning the assay.

183 Two replicate soil suspensions were prepared for each sample by placing $1 \mathrm{~g}$ of soil into a $150 \mathrm{~mL}$

184 beaker with $120 \mathrm{~mL}$ of deionized $\mathrm{H}_{2} \mathrm{O}\left(\mathrm{dH}_{2} \mathrm{O}\right)$. The soil was homogenized for 30 min using a 3.75

$185 \mathrm{~cm}$ magnetic stir bar and a stir plate set to $600 \mathrm{rpm}$. Soil suspension (100 $\mu \mathrm{L})$ was transferred with 
186 continuous stirring to microplate wells containing $50 \mu \mathrm{L}$ of modified universal buffer (MUB, $\mathrm{pH}$ 6),

187 using a multichannel pipette with four wide orifice tips, resulting in four microplate replicates from

188 each suspension for each assay. Methylumbelliferyl- $\beta$-D-glucoside or methylumbelliferyl-

189 phosphate substrate dissolved in water $(2 \mathrm{mM} ; 50 \mu \mathrm{L})$ was subsequently added to each well.

190 Following mixing by pipetting up and down 2 to 3 times, the plates were then covered, placed in a

191 shallow water bath and incubated at $37^{\circ} \mathrm{C}$ for $1 \mathrm{~h}$. Upon completing incubation, $50 \mu \mathrm{L}$ of Tris

192 (hydroxymethyl) aminomethane (THAM) pH 10 was added to each well to bring the reaction

193 mixtures to a pH that optimizes MUF fluorescence (pH 10 to $\mathrm{pH}$ 11) (Deng et al., 2013). Relative

194 fluorescence was measured at $360 \mathrm{~nm}$ excitation and $460 \mathrm{~nm}$ emission. The volume in each reaction

195 well during incubation was $200 \mu \mathrm{L}$, and the total volume after reaction termination was $250 \mu \mathrm{L}$. The

196 labs did not use the same model microplate readers; however sensitivity (gain) settings based on the

197 highest calibration standard were used to normalize results.

198 In addition to the four assay sample replicates, four control replicates were prepared for each 199 suspension in the same way, except substrate was added after incubation and THAM addition. Four 200 additional controls for autohydrolysis (AH) were set up one time only for each substrate, in which $201 \mathrm{dH}_{2} \mathrm{O}$ was used in the place of soil suspension, and substrate was added to two of the $\mathrm{AH}$ controls 202 before incubation, and to two AH controls after incubation and THAM addition. Reagents were not

203 all purchased from the same manufacturer because of limited availability and accessibility of

204 laboratories involved in the study. However, controls employed in the assay accounted for substrate 205 hydrolysis from substrate source and/or storage.

206 A soil-specific calibration curve was developed for each sample at the same time the assay

207 was performed, using the same procedure and soil suspensions, except $50 \mu \mathrm{L}$ of each MUF standard

208 was used in place of MUF substrate. Microplate wells of the prepared standards contained 0, 250, 
$500,1000,1500$ or 2500 total pmol MUF. An average slope was obtained for each soil from two

210 sets of standards (one from each replicate soil suspension), and was used to calculate enzyme

211 activity $\left(\mu \mathrm{mol} \mathrm{g}^{-1}\right.$ dry soil $\left.\mathrm{h}^{-1}\right)$.

212 PNP Bench-scale Enzyme Assay

213 The bench-scale method was performed as described previously (Tabatabai, 1994; Tabatabai

214 and Bremner, 1969), but without the use of toluene (Drouillon and Merckx, 2005; Vuorinen and

215 Saharinen, 1996). All reagents were brought to $37^{\circ} \mathrm{C}$ prior to performing the assay. Two assay

216 replicates were performed for each soil by weighing $1 \mathrm{~g}$ of soil into a $50 \mathrm{~mL}$ Erlenmeyer flask,

217 adding $4 \mathrm{~mL}$ of MUB (pH 6.0) and $1 \mathrm{~mL}$ of $0.05 \mathrm{M} p$-nitrophenyl- $\beta$-D-glucoside or $p$-nitrophenyl

218 phosphate, and then stoppering and swirling the flask to mix. A control was prepared for each

219 sample following the same procedure, but with substrate added after the reaction was terminated;

220 Flasks were incubated at $37^{\circ} \mathrm{C}$ for $1 \mathrm{~h}$. Following incubation, $4 \mathrm{~mL}$ of THAM pH 12 and $1 \mathrm{~mL}$ of

$2210.5 \mathrm{M} \mathrm{CaCl}_{2}$ were added, swirled to mix, and the suspension was passed through a Whatman \#2

222 filter. Filtrate absorbance was measured at $405 \mathrm{~nm}$ on spectrophotometer. Absorbance values from

223 both controls were subtracted from those obtained for samples prior to calculating the amount of $p$ -

224 nitrophenol released during the incubation using a standard calibration curve, which was developed

225 using the same procedure as for samples and with standards containing $0,100,200,300,400$ or 500

$226 \mathrm{nmol} p$-nitrophenol in MUB. Dilutions of the sample filtrates were made with a 1:1 mixture of

227 MUB pH 6.0 and $0.1 \mathrm{M}$ THAM pH 12 when color intensity exceeded that of the highest $p$ -

228 nitrophenol standard solution.

\section{Data analysis}

The SAS Univariate procedure (SAS version 9.3) was used to evaluate distribution of the

231 data. Significant differences among soils and labs were determined using one-way analysis of 
232 variance (ANOVA) and interactions between soil and lab factors were evaluated by 2-way ANOVA.

233 Individual contrasts were subsequently analyzed using Tukeys HSD $(p \leq 0.05)$ post-hoc test. Simple

234 correlation procedure (PROC CORR, SAS, 1999) was used to examine relationships between

235 enzyme activity between the MUF microplate and bench methods.

236 To identify the source of variation between the methods and the degree of variation among

237 the labs, coefficients of variation (CV) were calculated as standard deviation divided by the mean,

238 and multiplied by 100 to convert to percentages. For the microplate method, the variability within

239 suspensions was determined by calculating CVs using mean assay values, while those accounting

240 for field replications were calculated using averaged activities from the two suspensions. Similarly,

241 CVs accounting for the spatial and field scale of variability for the bench method were calculated

242 using means from the replicate suspensions.

\section{Results and Discussion}

245 The selected soils were quite different in physical and chemical properties (Table 1). The $\mathrm{pH}$ values

246 ranged from 5.2 to 7.3. Organic C varied widely, with over twofold more in the unmanaged Jory

247 soil than the cultivated Ottokee soil. The higher organic C levels are likely due to the higher clay

248 content of Jory and Miamian soils. However, in the case of the managed Jory soil, long-term

249 Christmas tree cultivation has led to significant reduction in organic $\mathrm{C}$ content (Table 1). At this site,

250 Christmas trees have been planted and harvested at about 5-year intervals and were sprayed with

251 herbicides. Additionally, the Christmas tree operation keeps the inter-row area vegetation free. As a

252 result, organic matter input to the soil was greatly reduced, and regular disturbance from equipment

253 and tree harvesting has likely reduced soil organic matter in the managed Jory soil compared to the

254 unmanaged forest Jory soil. 
Both enzyme methods detected differences in activities between soil types or within a soil

256 type (Jory soil) under different management practices (Table 2). Across both methods and for both

257 enzymes, the unmanaged Jory soil consistently had the highest activities. For the most part, enzyme

258 activities were highly correlated with clay content (Allison and Jastrow, 2006). Acid

259 phosphomonoesterase activity was lowest in the sandy soil, Ottokee, which was expected as this

260 soil had significantly lower levels of clay, organic C and microbial biomass (EL-FAME) than the

261 other soils. However, $\beta$-glucosidase activity was lowest in the Miamian soil even though it has

262 significantly higher clay content than the Ottokee soil.

\section{Bench vs. Microplate}

264 While there were clearly differences in enzyme activities detected by PNP bench-scale vs.

265 MUF microplate methods, the relative ranking of the soils was basically the same for both methods, 266 especially for acid phosphomonoesterase activity (Table 2). Correlations between bench and

267 microplate assays were strong for both enzymes, although slightly stronger for acid

268 phosphomonoesterase $(r=0.93)$ than $\beta$-glucosidase $(r=0.81)$ (data not shown).

Averaging the field replicates across all labs, the PNP bench-scale method consistently gave

270 higher activities than those measured with the MUF microplate method (Table 2). For Jory managed,

271 Jory unmanaged, Miamian, and Ottokee soils, mean activities of acid phosphomonoesterase by

272 MUF microplate method were 73, 71, 67 and 28\%, respectively, of those detected using the PNP

273 bench method; while mean $\beta$-glucosidase activities determined by the MUF microplate method

274 were 88, 93, 81 and 75\%, respectively, of those measured by the PNP bench method.

275 Higher enzymes activities detected by PNP bench over MUF microplate methods are consistent

276 with the results of Marx et al. (2001) and Trap et al., (2012). However, in the case of Marx et al.

277 (2001) this difference between the methods could be due to use of different incubation temperatures 
278 (microplate assays at 30 vs. $37^{\circ} \mathrm{C}$ for bench method). Drouillon and Merckx (2005) for

279 phosphomonoesterase activity on a wide range of soils, found the PNP method was significantly

280 lower than the MUF microplate method - nor were the activities of the two methods correlated.

281 However, their assays were run at the soil $\mathrm{pH}$. Variations in $\mathrm{pH}$ of these soils could have affected

282 the comparability of phosphatase activities detected by the 2 methods. In contrast, some studies did

283 not find significant differences between the two methods for N-actyl- $\beta$-D-glucosaminidase (Popova

284 and Deng, (2010) and for $\beta$-glucosidase (Dick et al., 2013) in diverse soil types. Deng et al. (2013)

285 found that $\mathrm{N}$-actyl- $\beta$-D--glucosaminidase, $\beta$-glucosidase, and acid phosphomonoesterase activities

286 in 16 soils were often significantly different (mostly with PNP being greater than MUF) but were in

287 the same order of magnitude. As with this study, they found that activities determined by the two

288 methods were significantly correlated.

289 The differences between the PNP and MUF-based methods in this study were not consistent

290 across soil types and enzymes. There are likely a number of factors for differences between the

291 methods that mechanistically cannot be isolated. Although there is greater affinity by MUF over

292 PNP (Km values presented by Marx et al, 2001; Deng et al., 2013) which could change the activity

293 rate, it should be a consistent effect. A more likely factor contributing to variability detected by the

294 MUF method is quenching of the emitted fluorescence by soil particles. The degree of quenching

295 varies temporally and spatially both within soil replicates as a function of uneven particle

296 distribution resulting from pipetting variations, and between soil replicates as a function of

297 differences in SOM content (Freeman et al., 1995). In theory, quenching of MUF in soil can be

298 accounted for by having a standard calibration curve for each soil, but this is confounded by

299 variations in particle density inherent to pipetting soil slurries. The resulting higher analytical 
variability of the MUF microplate method (Tables 3 to 6) could explain some of the inconsistencies

301 between the MUF microplate and PNP bench methods.

Although there were differences between the two methods, the differences were within an

303 order of magnitude and did not alter the ranking of soil types between the two methods as discussed

304 earlier. Furthermore, activities for the same enzyme in the same soil were highly correlated,

305 suggesting that the same pool or a large portion of overlapping pools of enzymes were detected by

306 the different approaches. This finding is supported by studies of Marx et al. (2001) and Dick et al.

307 (2013) who reported similar $\mathrm{V}_{\max }$ for PNP- and MUF-based substrates in the detection of $\beta$ -

308 glucosidase and acid phosphomonoesterase activities using the microplate format assays.

309 Because the soils were air-dried, the time between sampling and analysis likely did not

310 affect enzyme activities detected by either assay method. We did a preliminary study showing $\beta$ -

311 glucosidase on 2 diverse soils where the activity on air dried soil was constant $\mathrm{p}$ to 6 months

312 (personal communication R Dick). Enzyme analyses were conducted from 3 to 6 weeks after soils

313 were sampled, sieved, homogenized, and air-dried. The results were much closer for replicates of

314 the same soil sample than between soil type providing evidence that the storage time that varied

315 across labs was not a factor (meaning air dried samples were stable over time). This is in line with

316 Bandick and Dick (1999) who showed that air drying soils for a range of enzyme activities

317 (including acid phosphomonoesterase and $\beta$-glucosidase activity) did not alter the ranking of soil

318 samples compared to analyses on fresh, field moist samples. The ability to use air-dried soil is an

319 advantage over most other microbial properties that require rapid analysis on fresh soils.

320 Commercial labs often prefer the use of dried soils to accommodate for varying shipping times.

321 To give some insight into the relationship between the two enzyme activities assayed by

322 bench and microplate methods and microbial community profiles, fatty acid methyl esters (EL- 
323 FAMEs) were used as biomarkers for major functional microbial groups. The biomass of each

324 microbial group was correlated with enzyme activities (Table 3). For both acid

325 phosphomonoesterase and $\beta$-glucosidase, $r$ values were mostly similar for MUF microplate and

326 PNP bench method correlation with EL-FAME biomarkers. Interestingly, the arbuscular

327 mycorrhizal fungal marker was poorly correlated to $\beta$-glucosidase activity, but significantly

328 correlated to acid phosphomonoesterase activity by both assay methods. The results support the

329 conclusion that both enzyme methods detected activities from the same pools of enzymes in soil.

330 Furthermore, these results suggest that there is a relationship between enzyme activities and the size

331 of various microbial groups, and differences in the potential of these groups to produce $\beta$ -

332 glucosidase and acid phosphomonoesterase.

\section{Laboratory Comparisons}

334 Differences among labs were observed, and some were statistically significant (Table 2). A

335 2-way ANOVA of the lab by soil type factors had a significant interaction $(\mathrm{P}<0.001)$. For both

336 microplate and bench assays, there were slightly fewer significant differences among labs for $\beta$ -

337 glucosidase activity than were observed for acid phosphomonoesterase activity. Labs 3 and 4 tended

338 to report higher enzyme activities compared to Labs 1 and 2 (both for MUF and PNP assays),

339 whereas Lab 5 tended to report the lowest activities (MUF assay only). However, these differences

340 were not always significant. Although there were differences between labs for both methods within

341 a soil type, the mean values and ranking of the soils were very similar among the labs. Thus,

342 differences among labs were small compared to differences among soils, and are more likely a

343 reflection of low variance within each lab which enabled significant $(\mathrm{P}<0.05)$ detection of small

344 differences among labs. However, it should be pointed out that analysis of variance can only

345 determine differences between treatments and does not determine whether treatments are the same 
346 on a probability basis. Thus, although there were at times small differences between labs for either

347 enzyme method under evaluation, each lab's results would largely lead to the same conclusion in

348 ranking the soil samples.

\section{Levels of Variability Between and Within Assay Methods}

350 Coefficients of variation (CVs) were calculated for each lab and soil by enzyme assay for

351 the MUF microplate method at three levels: microplate (four replicates); soil suspension (two

352 replicates); and field (three replicates) (Tables 4 and 5). Average CVs across all soil samples and

353 labs for the microplate method were $14 \%$ and $18 \%$ for acid phosphomonoesterase and $\beta$ -

354 glucosidase activities, respectively. At the suspension level, average CVs were 12 and $11 \%$, 355 respectively.

356 Coefficients of variation among the four replicate microplate wells ranged from 2 to $118 \%$

357 (Tables 4 and 5). The highest CVs tended to occur in the sandy (Ottokee) soil at all levels

358 replication (microplate and suspension). At the suspension level for the MUF microplate method,

359 CVs ranged from 0 to $48 \%$ (Tables 4 and 5). Eleven of the $15 \mathrm{CVs}$ in the sandy soil were greater

360 than $10 \%$, comparing to other soils where 2 to 5 of the $15 \mathrm{CVs}$ were greater than $10 \%$. However, it

361 should be pointed out that the CVs would naturally be high simply because of the low number of

362 replications $(\mathrm{n}=2)$. Sandy soils are inherently difficult to homogenize and dispense. Although the

363 observed difference is not unexpected, this may affect precision when using microplate methods.

364 These results suggest that greater suspension and microplate replication are needed to reduce the

365 variability for sandy soils. Similar, but somewhat lower variability was also observed in the PNP

366 bench method.

367 Pipetting error is another potential source of variability for the MUF assay due to the

368 difficulty of evenly dispensing $\mu \mathrm{L}$-scale volumes of soil suspensions and the possibility of soil 
particles clogging the pipette tips and going unnoticed by the operator. Other sources of error

370 associated with reagents (e.g. sources and reagent make up) and experimental conditions (e.g.

371 managing temperature) would likely cause a systemic error or variation that is constant across all

372 samples within a lab (thus contributing to differences among labs but not within a lab). Average

373 CVs by lab across all soil samples ranged from $14 \%$ (lab 1) to $23 \%$ (lab 5) for $\beta$-glucosidase

374 activities (Table 4) and $13 \%$ (lab 2) to $17 \%$ (lab 5) for acid phosphomonoesterase activities (Table 375 5).

For the PNP bench method, the source of variation equivalent to MUF microplate

377 suspension is assay replication ( $\mathrm{n}=2$ for bench method) (Tables 6 and 7 ), which overall had lower

378 CVs than the MUF microplate suspensions (Tables 6 and 7). Averaging across all soil samples and

379 labs for the PNP bench method, the CVs ranged from $4 \%$ (lab 1) to $5 \%$ (lab 3) and $3 \%$ (lab 2) to

$3806 \%$ (lab 3) for acid phosphomonoesterase and $\beta$-glucosidase activities, respectively. An advantage

381 of the bench method is that one gram of soil is used in each assay compared to the $0.83 \mu \mathrm{g}$ in each

382 microplate well. This could be a major factor contributing to the substantially lower CVs of the

383 bench over the microplate methods at the analytical level of replication. Alternatively, the

384 microplate method allows for very small samples to be analyzed for studies at small spatial scales.

385 From a practical perspective, it is easier to increase the replicates on the microplate than it is

386 to increase suspension replication, especially considering the 30 minutes required for

387 homogenization of each suspension. Many laboratories include as many as 16 replicate wells per

388 suspension (e.g. following the protocol of Saiya-Cork et al. 2002). However, replications of the

389 same soil suspension account mainly for pipetting error, and do not account for errors originating

390 from soil heterogeneity and/or treatments under evaluation. Results from this study suggest that

391 activities obtained from two suspensions were consistent. This is in agreement with Dick et al 
392 (2013), who did an in-depth analysis of the reproducibility of the suspension step in the MUF

393 microplate method.

394 At the field level, CVs ranged from $1 \%$ to $90 \%$ among field replicates for the MUF assay,

395 and $2 \%$ to $60 \%$ for the PNP assay, also with higher CVs in the sandy soil. Again, the bench-scale

396 method resulted in CVs that were generally lower than those for the MUF microplate method.

397 A factorial analysis of mean activity for each assay across all four soils for each lab, and

398 across all five labs for each soil showed significant differences based on both lab and soil (Table 2).

399 Means of field replicate across all labs for each soil showed some significant differences, except in

400 the sandy (Ottokee) soil, which may have been the result of the greater variability discussed above.

401 Standardization of the MUF Microplate Method

402 The MUF microplate method has a number of protocol conditions or nuances that could

403 make it difficult to obtain reproducible results by different operators and/or lab equipment. These

404 include the need to fully suspend soils in solution, maintain buffer $\mathrm{pH}$ (Lakowicz, 1983) and a

405 constant temperature throughout the incubation (Lakowicz, 1983), accurately pipette $\mu \mathrm{L}$ volumes,

406 and carefully account for quenching. An alternative protocol as outlined by Marx et al (2001) is not

407 to add base and then to measure the linear increases in fluorescence. This omits the no-substrate

408 control and potentially produces more accurate quantification of the enzymatic reaction rates based

409 on multiple data points rather than one single data point. However, a calibration curve is needed

410 under identical assay conditions. This method is also considerably less sensitive. As shown in Deng

411 et al. (2013), the relative MUF florescence signal at $\mathrm{pH} 10$ could be greater than 35000 times of

412 those at $\mathrm{pH}$ 6. However, German et al. (2011) found that florescence signal was detectable in soils

413 with $\mathrm{pH} \geq 4.5$. 
Methods used to prepare soil suspensions are rarely reported in the literature. Creating soil

415 suspensions could be a major source of variation between labs, as type of homogenizer, size of

416 glassware and stir bars, and differences in mixing speed and time could all affect the outcome. For

417 this study, all labs followed the same soil suspension protocol (container, stir bar size, and stirring

418 time and speed). This is a protocol point that should be considered as a standard inclusion for

419 describing the MUF microplate method in the literature. Indeed, the basic soil suspension protocol

420 followed in this study is based on the investigation of various factors that might affect soil

421 suspension reproducibility as reported by Dick et al. (2013). They found using a stir bar provided

422 reproducible results across 6 suspension replications for both a loamy soil and a sandy soil for the

423 MUF microplate method.

424 Quenching was accounted for in the current study by using a standard curve for each soil.

425 Variation in the amount of minerals and organic matter in each well affect the degree of quenching

426 and therefore variability of the results. Temperature control is important as well because MUF

427 florescence is very sensitive to temperature (Guilbault, 1990). We found that it is important to have

428 all reagents at the incubation temperature prior to starting the substrate-soil incubation because it

429 could take nearly 30 minutes of the incubation time to allow reaction mixtures to reach the protocol

430 temperature of $37^{\circ} \mathrm{C}$.

431 It is also important to note that we used the optimal $\mathrm{pH}$ to maximize the activity of each

432 enzyme (based on previous reports in the literature). Some researchers have argued that the

433 incubation solution should be left unbuffered or adjusted to $\mathrm{pH}$ of the assayed soil (Drouillon and

434 Merckx, 2005; German et al. 2011), with the goal to obtain in situ enzyme activities in the field.

435 However, doing so prevents direct comparisons across studies and among different soils, which

436 were goals of this study. Furthermore, if there are no treatment effects, it cannot be concluded that 
437 there were no differences because it could be that it was simply due to using the non-optimized

438 conditions of the assay. To determine what the optimal $\mathrm{pH}$ is for a given enzyme assay the reader is

439 referred to Dick (2011) which is a comprehensive compilation of vetted methods, largely done by

440 Tabatabai and co-workers, where each method has a recommended optimal $\mathrm{pH}$. However, to be

441 absolutely certain of the optimal $\mathrm{pH}$ for specific soils, $\mathrm{pH}$ curves should be developed before

442 proceeding with investigations that use particular enzyme assays.

443 In this study, THAM buffer at $\mathrm{pH} 10$ was used instead of $\mathrm{NaOH}$ to terminate the reaction.

444 Deng et al. (2013) reported that fluorescence of MUF is not stable in the presence of $\mathrm{NaOH}$ and that

445 THAM at $\mathrm{pH}$ 10-11 is optimal for maintaining fluorescence. We imposed a one-hour maximum for

446 taking the readings after THAM addition (effectively terminating the reaction). This is because

447 fluorescing expends energy, and once initiated fluoresce decreases over time. Hence, we

448 recommend that this be a standard description in MUF microplate methods, and that authors report

449 on how quickly the fluorescence was read.

450 We propose that the detailed MUF microplate method described in the Supplemental

451 Section be the standard protocol except that the buffer $\mathrm{pH}$ for the incubation be adjusted to the

452 optimal level according to the enzyme of interest. In brief we are suggesting that the following

453 operationally defined protocols be adopted: $37^{\circ} \mathrm{C}$ incubation temperature, $\mathrm{pH} 10$ THAM buffer to

454 terminate the enzymatic reaction, 1 hour incubation, controlling for quenching in standard curve and 455 autohydrolysis, pre-warming incubation reagents, and method of developing soil suspension. These

456 can be adopted because the results of MUF microplate method to that of PNP bench method were

457 quite similar in absolute values and in ranking of the soil treatments. It should be noted that the

458 optimum $\mathrm{pH}$ for the enzyme assays where this is known, is largely based on soils from temperate

459 regions (Tabatabai, 1994). As such further investigations are warranted on soils from other regions, 
460 as variation across soils for enzyme sources and stabilization, and/or soil chemistry could affect

461 optimum assay $\mathrm{pH}$ for a given soil.

\section{Conclusions}

463 The MUF microplate and bench methods each have advantages and disadvantages. The

464 MUF microplate method in theory should be a high throughput method. From our experience this is

465 the case if multiple enzymes are assayed together. However, if the assay is for one enzyme with

466 multiple soil samples it is less clear that the microplate method takes less time because of the need

467 to set up soil suspensions which is time consuming and takes considerable bench space. One

468 additional advantage of the MUF microplate assay is the ability to do the assay on small amounts of

469 soils (but only if the soil:solution ratio is kept the same as when $1 \mathrm{~g}$ of soil is put into solution).

470 To enable cross-literature comparisons and meta-analyses, it is important to employ enzyme

471 assay protocols that minimize the potential for operator biases and generate reproducible results

472 across labs. The MUF microplate method increases the number of points at which the operator can

473 influence outcomes. These include homogenization and suspension of soil, retrieval and dispensing

474 of $\mu \mathrm{L}$ volumes of soil slurries, and reading on a fluorimeter or spectrophotometer (DeForest, 2009;

475 German et al., 2011; Trap et al., 2012). Of these, the most likely source of variation from an

476 operator perspective is pipetting. Indeed, in this study overall variability was highest for replication

477 on the microplate $(\mathrm{n}=4)$, and the suspension replication actually had lower CVs with $\mathrm{n}$ only

478 equaling 2. In comparison, the bench-scale method had significantly lower CVs for analytical and

479 field replicates than the MUF microplate method. Most likely this is due the much larger soil

480 amount that is used at the bench scale.

481 It has become increasingly apparent that MUF microplate protocols require very tight

482 standardization and greater replication in order to yield results that are comparable either within or 
483 across laboratories. In the current study, effort was made to control for methodological differences

484 by using air-dried soils (therefore more stable over varying storage periods) and identical assay

485 protocols and method for soil homogenization. Reagents were preheated and incubated in a water

486 bath. Microplate reader sensitivity was set to the highest standard, readings were taken within an

487 hour of base addition, and controls were included for substrate autohydrolysis.

488 When all labs adhered to a strict and consistent protocol, the differences among lab results

489 were much smaller than differences due to soil type. In this study, the results for both bench and

490 MUF microplate method from different labs were quite similar in terms of ranking of soil

491 management treatments and soil types (Table 2). This suggests that different labs can come to the

492 same conclusions on the same set of soil samples using a standardized MUF microplate protocol.

493 
Allison, S.D., Jastrow, J.D., 2006. Activities of extracellular enzymes in physically isolated

Association of Official Agricultural Chemists, 2006. AOAC Task Force recommends best practices

Bandick, A.K., Dick, R.P., 1999. Field management effects on soil enzyme activities. Soil Biol.

DeForest, J.L., 2009. The influence of time, storage temperature, and substrate age on potential soil enzyme activity in acidic forest soils using MUB-linked substrates and 1-DOPA. Soil Biol. Biochem. 41, 1180-1186.

Deng, S., Kang, H., Freeman, C., 2011. Microplate fluorimetric assay of soil enzymes in: Dick, R.P. (Ed.), Methods of Soil enzymology. Soil Science Society of America, Madison, WI, pp. 311-318.

Deng, S.P., Popova, I.E., Dick, L., Dick, R., 2013. Bench scale and microplate format assay of soil enzyme activities using spectroscopic and fluorometric approaches. Appl. Soil Ecol. 64, 8490.

Drouillon, M., Merckx, R., 2005. Performance of para-nitrophenyl phosphate and 4methylumbelliferyl phosphate as substrate analogues for phosphomonoesterase in soils with different organic matter content. Soil Biol. Biochem. 37, 1527-1534.

Dick, L.K., Jia, G., Deng, S., Dick, R.P., 2013. Evaluation of Microplate and Bench-scale $\beta$ glucosidase Assays for Reproducibility, Comparability, Kinetics, and Homogenization Methods in Two Soils. Biol. Fertility Soils In Press.

Eivazi,F., Tabataabai, M.A., 1988. Glucosidases and galactosidase in soils. Soil Biol. Biochem. 20, 601-606

Drouillon, M., Merckx, R., 2005. Performance of para-nitrophenyl phosphate and 4methylumbelliferyl phosphate as substrate analogues for phosphomonoesterase in soils with different organic matter content. Soil Biol. Biochem. 37, 1527-1534.

Fem Microbiology Action Team, 2009. Method validation of U.S. Environmental Protection Agency microbiological methods of analysis. Fem Document Number2009-01. October 7, 2009.

Freeman, C., Liska, G., Ostle, N.J., Jones, S.E., Lock, M.A., 1995. The use of fluorogenic substrates for measuring enzyme-activity in peatlands. Plant and Soil 175, 147-152.

Frostegard, A., and E. Bååth. 1996. The use of phospholipid fatty acid analysis to estimate bacterial and fungal biomass in soil. Biology and Fertility of Soils 22:59-65. 
German, D.P., Weibtraub, M.N., Grandy, A.S., Lauber, C.L., Rinkes, Z.L., Allison, S.D., 2011. Optimization of hydrolytic and oxidative enzyme methods for ecosystem studies. Soil Biol. Biochem. 43, 1387-1397.

Green, J.M., 1996. A practical guide to analytical method validation. Anal. Chem. 68, 305A-309A.

Guilbault, G.G., 1990. Practical Fluorescence, Second Edition ed. Marcel Dekker, Inc., New York.

Lakowicz, J.R., 1983. Principles of Fluorescence Spectroscopy. Plenum Press, New York.

Marx, M.C., Wood, M., Jarvis, S.C., 2001. A microplate fluorimetric assay for the study of enzyme diversity in soils. Soil Biol. Biochem. 33, 1633-1640.

Popova, I.E., Deng, S., 2010. A high-throughput microplate assay for simultaneous colorimetric quantification of multiple enzyme activities in soil. Appl. Soil Ecol. 45, 315-318.

Pritsch, K., Raidl, S., Marksteiner, E., Blaschke, H., Agerer, R., Schloter, M., Hartmann, A., 2004. A rapid and highly sensitive method for measuring enzyme activities in single mycorrhizal tips using 4-methylumbelliferone-labelled fluorogenic substrates in a microplate system. J. Microbiol. Methods 58, 233-241.

SAS Institute Inc., 1999. SAS User's Guide: Statistics. SAS Institute Inc, Cary, NC.

Schutter, M.E., and R.P. Dick. 2000. Extraction methods of fatty acids for microbial community structure analysis. Soil Sci. Soc. Am. J. 64:1659-1668.

Tabatabai, M.A., 1994. Soil enzymes, in: Weaver, R.W., Angle, J.S., Bottomley, P.S. (Eds.), Methods of Soil Analysis part 2. Microbiological and Biochemical Properties. Soil Science Society of America, Madison, WI, pp. 775-833.

Tabatabai, M.A., Bremner, J.M., 1969. Use of $\rho$-nitrophenyl phosphomonoesterase for assay of soil phosphomonoesterase activity. Soil Biol. Biochem. 1, 301-307.

Trap, J., Riah, W., Akpa-Vinceslas, M., Bailleul, C., Laval, K., Trinsoutrot-Gattin, I., 2012. Improved effectiveness and efficiency in measuring soil enzymes as universal soil quality indicators using microplate fluorimetry. Soil Biol. Biochem. 45, 98-101.

Vuorinen, A.H., Saharinen, M.H., 1996. Effects of soil organic matter extracted from soil on acid phosphomonoesterase. Soil Biol. Biochem. 28, 1477-1481. 


\begin{tabular}{|c|c|c|c|c|c|c|c|}
\hline Soil & Vegetation & pH & Total C & Total N & Sand & Silt & Clay \\
\hline & & & \multicolumn{2}{|c|}{-----------g kg-1 -------- } & \multicolumn{3}{|c|}{-----------------\%o----------- } \\
\hline $\begin{array}{l}\text { Jory silty clay loam (fine, mixed, } \\
\text { active mesic Xeric palehumult) }\end{array}$ & $\begin{array}{l}\text { Christmas trees } \\
\text { (managed) }\end{array}$ & 5.2 & 27.9 & 2.2 & 46 & 38 & 16 \\
\hline $\begin{array}{l}\text { Jory silty clay loam (fine, mixed, } \\
\text { active mesic Xeric palehumult) }\end{array}$ & $\begin{array}{l}\text { Douglas Fir } \\
\text { (unmanaged) }\end{array}$ & 6.0 & 36.8 & 2.7 & 52 & 34 & 14 \\
\hline $\begin{array}{l}\text { Miamian silt loam (fine, mixed, } \\
\text { active, mesic Oxyaquic Hapludalfs) }\end{array}$ & $\begin{array}{l}\text { Mixed grasses } \\
\text { (unmanaged) }\end{array}$ & 5.8 & 27.9 & 2.0 & 38 & 40 & 22 \\
\hline $\begin{array}{l}\text { Ottokee fine sand (mixed, mesic } \\
\text { Aquic Udipsamnents) }\end{array}$ & $\begin{array}{l}\text { Row cropped } \\
\text { (managed) }\end{array}$ & 7.3 & 17.6 & $\mathrm{ND} \dagger$ & 90 & 8 & 2 \\
\hline
\end{tabular}

$\uparrow$ Not detectable. 
Table 2. Soil enzyme activities by bench or microplate methods across labs

\begin{tabular}{|c|c|c|c|c|c|c|}
\hline \multirow[b]{3}{*}{$\mathrm{La}$} & & $\begin{array}{c}\text { Jory } \\
\text { Managed }\end{array}$ & $\begin{array}{c}\text { Jory } \\
\text { Unmanaged }\end{array}$ & $\begin{array}{l}\text { Miamian } \\
\text { Unmanaged }\end{array}$ & $\begin{array}{c}\text { Ottokee } \\
\text { Row-Crop }\end{array}$ & \\
\hline & & \multicolumn{5}{|c|}{ 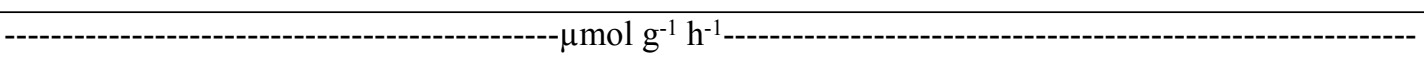 } \\
\hline & & \multicolumn{4}{|c|}{ PNP bench-scale acid phosphomonoesterase } & $\square$ \\
\hline 1 & & $1.93 b^{\dagger}(0.179)^{\dagger \dagger}$ & $3.90 \mathrm{~b}(0.092)$ & $3.18 \mathrm{bc}(0.343)$ & $0.49 \mathrm{a}(0.219)$ & $2.38 \mathrm{~B}+$ \\
\hline 2 & & $1.76 \mathrm{~b} \quad(0.156)$ & $3.30 \mathrm{c}(0.277)$ & $2.76 \mathrm{c}(0.221)$ & $0.42 \mathrm{a}(0.218)$ & $2.06 \mathrm{C}$ \\
\hline 3 & & $2.31 \mathrm{a} \quad(0.143)$ & $4.38 \mathrm{a}(0.187)$ & $3.95 \mathrm{a}(0.468)$ & $0.55 \mathrm{a}(0.280)$ & $2.80 \mathrm{~A}$ \\
\hline 4 & & $2.07 \mathrm{ab}(0.071)$ & $4.55 \mathrm{a}(0.168)$ & $3.87 b(0.490)$ & $0.81 \mathrm{a}(0.297)$ & $2.83 \mathrm{~A}$ \\
\hline 5 & & $\mathrm{NA}$ & NA & NA & NA & NA \\
\hline & $\square$ & $2.02 \mathrm{C}+\mathrm{t}$ & $4.03 \mathrm{~A}$ & $3.44 \mathrm{~B}$ & $0.57 \mathrm{D}$ & \\
\hline \multicolumn{7}{|c|}{ MUF microplate acid phosphomonoesterase } \\
\hline 1 & & $1.40 \mathrm{~b}(0.076)$ & $2.75 b(0.233)$ & $1.97 \mathrm{a}(0.438)$ & $0.19 \mathrm{a}(0.065)$ & $1.58 \mathrm{BC}$ \\
\hline 2 & & $1.50 \mathrm{~b}(0.081)$ & $2.94 b(0.191)$ & $2.23 \mathrm{a}(0.442)$ & $0.16 \mathrm{a}(0.071)$ & $1.71 \mathrm{~B}$ \\
\hline 3 & & $1.88 \mathrm{a}(0.085)$ & $2.68 b(0.225)$ & $2.38 \mathrm{a}(0.264)$ & $0.18 \mathrm{a}(0.044)$ & $1.78 \mathrm{AB}$ \\
\hline 4 & & $1.24 \mathrm{~b}(0.325)$ & $3.85 \mathrm{a}(0.369)$ & $2.53 \mathrm{a}(0.304)$ & $0.14 \mathrm{a}(0.078)$ & $1.94 \mathrm{~A}$ \\
\hline 5 & & $1.34 \mathrm{~b}(0.087)$ & $1.99 \mathrm{c}(0.312)$ & $2.40 \mathrm{a}(0.483)$ & $0.14 \mathrm{a}(0.129)$ & $1.47 \mathrm{C}$ \\
\hline & $\square$ & $1.47 \mathrm{C}$ & $2.84 \mathrm{~A}$ & $2.30 \mathrm{~B}$ & $0.16 \mathrm{D}$ & \\
\hline \multicolumn{7}{|c|}{ PNP bench-scale $\beta$-glucosidase } \\
\hline 1 & & $0.54 \mathrm{~b}(0.015)$ & $1.14 \mathrm{a}(0.225)$ & $0.55 \mathrm{a}(0.038)$ & $0.68 \mathrm{a}(0.065)$ & $0.73 \mathrm{~B}$ \\
\hline 2 & & $0.50 \mathrm{~b}(0.045)$ & $1.08 \mathrm{~b}(0.170)$ & $0.55 \mathrm{a}(0.021)$ & $0.63 \mathrm{a}(0.215)$ & $0.69 \mathrm{~B}$ \\
\hline 3 & & $0.72 \mathrm{a}(0.036)$ & $1.60 \mathrm{a}(0.210)$ & $0.65 a(0.389)$ & $0.89 \mathrm{a}(0.235)$ & $0.97 \mathrm{~A}$ \\
\hline 4 & & $0.51 \mathrm{~b}(0.031)$ & $1.08 \mathrm{~b}(0.175)$ & $0.74 \mathrm{a}(0.110)$ & $0.72 \mathrm{a}(0.172)$ & $0.76 \mathrm{~B}$ \\
\hline 5 & & NA & NA & NA & NA & NA \\
\hline & $\square$ & $0.57 \mathrm{C}$ & $1.23 \mathrm{~A}$ & $0.62 \mathrm{BC}$ & $0.73 \mathrm{~B}$ & \\
\hline \multicolumn{7}{|c|}{$\underline{\text { MUF microplate } \beta \text {-glucosidase }}$} \\
\hline 1 & & $0.48 b c(0.006)$ & $1.28 \mathrm{a}(0.279)$ & $0.47 \mathrm{ab}(0.064)$ & $0.63 \mathrm{a}(0.258)$ & $0.72 \mathrm{~A}$ \\
\hline 2 & & $0.46 b c(0.038)$ & $1.18 \mathrm{a}(0.232)$ & $0.50 \mathrm{ab}(0.090)$ & $0.62 \mathrm{a}(0.193)$ & $0.69 \mathrm{~A}$ \\
\hline 3 & & $0.75 \mathrm{a} 0.115)$ & $1.33 \mathrm{a}(0.321)$ & $0.55 \mathrm{a}(0.085)$ & $0.57 \mathrm{a}(0.210)$ & $0.80 \mathrm{~A}$ \\
\hline 4 & & $0.53 b(0.206)$ & $1.39 \mathrm{a}(0.185)$ & $0.60 \mathrm{a}(0.035)$ & $0.56 \mathrm{a}(0.194)$ & $0.77 \mathrm{~A}$ \\
\hline 5 & & $0.28 \mathrm{c}(0.029)$ & $0.53 b(0.066)$ & $0.39 b(0.053)$ & $0.39 a(0.142)$ & $0.40 \mathrm{~B}$ \\
\hline & $\square$ & $0.50 \mathrm{~B}$ & $1.14 \mathrm{~A}$ & $0.50 \mathrm{~B}$ & $0.55 \mathrm{~B}$ & \\
\hline
\end{tabular}

\footnotetext{
†Values in a column within the same assay and soil type followed by the same lower case letter are not significantly different at $p=0.05$.

$\dagger$ Values in parentheses are standard deviations.

*Values in the mean column within an assay followed by the same upper case letter are not significantly different at $p=0.05$

$\$$ Values in the mean row within an enzyme method followed by the same upper case letter are not significantly different at $p=0.05$.
} 
Table 3. Pearson's correlation coefficients ( $\mathrm{r}$ values) for linear correlation between enzyme activities and biomass of microbial groups based on ester linked fatty acids (EL FAME) $(n=24)$.

\begin{tabular}{|c|c|c|c|c|}
\hline \multirow[t]{2}{*}{ Microbial Functional Group } & \multicolumn{2}{|c|}{ Acid Phosphomonoesterase } & \multicolumn{2}{|c|}{$\beta$-Glucosidase } \\
\hline & MUF Microplate & PNP Bench-scale & MUF Microplate & PNP Bench-scale \\
\hline Arbuscular mycorrhizal fungi & $0.64^{* * *}$ & $0.69 * * *$ & $0.19^{\mathrm{NS}}$ & $0.12^{\mathrm{NS}}$ \\
\hline Actinobacteria & $0.78 * * *$ & $0.75^{* * *}$ & $0.76^{* * *}$ & $0.70 * * *$ \\
\hline Gram-negative bacteria & $0.80 * * *$ & $0.81^{* * *}$ & $0.89 * * *$ & $0.85^{* * *}$ \\
\hline Gram-positive bacteria & $0.74^{* * *}$ & $0.71^{* * *}$ & $0.80 * * *$ & $0.75^{* * *}$ \\
\hline Total bacteria & $0.77^{* * *}$ & $0.76^{* * *}$ & $0.84^{* * *}$ & $0.79 * * *$ \\
\hline Total fungi & $0.81^{* * *}$ & $0.83^{* * *}$ & $0.83^{* * *}$ & $0.76^{* * *}$ \\
\hline
\end{tabular}


Table 4. Coefficients of variation (CV) at three levels of replication for $\beta$-glucosidase activity using the MUF microplate method.

\begin{tabular}{|c|c|c|c|c|c|c|c|c|c|c|c|c|c|c|c|c|c|c|c|c|c|c|c|c|}
\hline \multirow{3}{*}{$\begin{array}{l}\text { Replication } \\
\text { Source } \\
\text { Field } \\
\text { Suspension }\end{array}$} & \multicolumn{3}{|c|}{ Jory Managed } & \multicolumn{6}{|c|}{ Jory Unmanaged } & \multicolumn{7}{|c|}{ Miamian Unmanaged } & \multicolumn{8}{|c|}{ Ottokee Row Crop } \\
\hline & 1 & 2 & 3 & 1 & & 2 & \multicolumn{3}{|c|}{3} & \multicolumn{3}{|c|}{1} & \multicolumn{3}{|c|}{2} & 3 & \multicolumn{3}{|c|}{1} & \multicolumn{3}{|c|}{2} & \multicolumn{2}{|r|}{3} \\
\hline & 1 & 12 & 1 & 12 & & 2 & & 1 & 2 & 1 & 2 & & 1 & 2 & & 2 & 1 & 2 & & 1 & 2 & & 1 & 2 \\
\hline Lab & \multicolumn{24}{|c|}{ Variation of microplate analytical replications $(n=4)$ within a soil suspension } \\
\hline 1 & 8 & 4 & 17 & 46 & 6 & 811 & 11 & 19 & 17 & 7 & 11 & 11 & 9 & 15 & 15 & 104 & 13 & 48 & 48 & 22 & 26 & 26 & 24 & 36 \\
\hline 2 & 17 & $15 \quad 14$ & 17 & 7 & 8 & 10 & 10 & 9 & 10 & 22 & 18 & 18 & 4 & 21 & 21 & 14 & 12 & 20 & 20 & 38 & 118 & 118 & 19 & 13 \\
\hline 3 & 22 & 13 & 23 & 127 & 7 & 20 & 20 & 18 & 9 & 17 & 70 & 70 & 11 & 15 & 15 & 39 & 36 & 69 & 69 & 22 & 26 & 26 & 22 & 21 \\
\hline 4 & 21 & 6 & 14 & 18 & 9 & 13 & 6 & 24 & 38 & 17 & 14 & 14 & 9 & 9 & 9 & 10 & 6 & 11 & 11 & 11 & 30 & 30 & 10 & 9 \\
\hline 5 & 22 & 23 & 17 & 247 & 7 & 18 & 18 & 10 & 14 & 19 & 7 & 7 & 5 & 22 & 22 & 35 & 36 & 16 & 16 & 8 & 16 & 16 & 38 & 22 \\
\hline & \multicolumn{24}{|c|}{ Variation of soil suspensions ( $n=2)$} \\
\hline 1 & \multicolumn{2}{|r|}{15} & 4 & \multicolumn{2}{|l|}{2} & 9 & \multicolumn{3}{|c|}{9} & \multicolumn{3}{|c|}{3} & \multicolumn{3}{|c|}{19} & 1 & & 13 & & & 0 & & 0 & \\
\hline 2 & 9 & 2 & 16 & 4 & & 10 & & 7 & & & 10 & & & 14 & & 2 & & 3 & & & 15 & & 9 & \\
\hline 3 & 13 & 40 & 3 & 2 & & 4 & & 28 & & & 1 & & & 49 & & 13 & & 32 & & & 17 & & 21 & \\
\hline 4 & 4 & 11 & 13 & 14 & & 7 & & 1 & & & 5 & & & 9 & & 4 & & 5 & & & 9 & & 7 & \\
\hline 5 & 3 & 23 & 3 & 13 & & 1 & & 26 & & & 2 & & & 12 & & 18 & & 1 & & & 20 & & 20 & \\
\hline & & & & & & & & iatic & n of & Id re & plica & tion & $(n=$ & & & & & & & & & & & \\
\hline 1 & & 1 & & & & 22 & & & & & & & 1 & 4 & & & & & & & 41 & & & \\
\hline 2 & & 8 & & & & 20 & & & & & & & 1 & 8 & & & & & & & 31 & & & \\
\hline 3 & & 15 & & & & 24 & & & & & & & 1 & 5 & & & & & & & 37 & & & \\
\hline 4 & & 39 & & & & 13 & & & & & & & 6 & 3 & & & & & & & 35 & & & \\
\hline 5 & & 10 & & & & 12 & & & & & & & 1 & 4 & & & & & & & 37 & & & \\
\hline
\end{tabular}


Table 5. Coefficients of variation (CV) at two levels of replication for acid phosphatase activity using the bench method (Lab \#4 did not replicate the bench method, and Lab \#5 did not perform the bench-scale assay).

\begin{tabular}{|c|c|c|c|c|c|c|c|c|c|c|c|c|}
\hline \multirow[t]{3}{*}{ Lab } & \multicolumn{3}{|c|}{ Jory Managed } & \multicolumn{3}{|c|}{ Jory Unmanaged } & \multicolumn{3}{|c|}{ Miamian Unmanaged } & \multicolumn{3}{|c|}{ Ottokee Row Crop } \\
\hline & 1 & 2 & 3 & 1 & 2 & 3 & 1 & 2 & 3 & 1 & 2 & 3 \\
\hline & \multicolumn{12}{|c|}{ Variation of analytical replications $(n=2)$} \\
\hline 1 & 3 & 4 & 2 & 2 & 2 & 2 & 2 & 3 & 0 & 13 & 2 & 8 \\
\hline 2 & 1 & 1 & 0 & 3 & 4 & 16 & 2 & 2 & 4 & 3 & 3 & 8 \\
\hline \multirow[t]{2}{*}{3} & 1 & 2 & 7 & 7 & 7 & 6 & 2 & 1 & 1 & 0 & 13 & 14 \\
\hline & \multicolumn{12}{|c|}{ Variation of field replications $(n=3)$} \\
\hline 1 & & 9 & & & 2 & & & 11 & & & 45 & \\
\hline 2 & & 9 & & & 8 & & & 8 & & & 52 & \\
\hline 3 & & 6 & & & 4 & & & 12 & & & 51 & \\
\hline 4 & & 3 & & & 4 & & & 13 & & & 37 & \\
\hline
\end{tabular}


Table 6. Coefficients of variation (CV) at two levels of replication for $\beta$-glucosidase activity using the bench method (Lab \#4 did not replicate the bench method, and Lab \#5 did not perform the bench-scale assay).

\begin{tabular}{|c|c|c|c|c|c|c|c|c|c|c|c|c|}
\hline \multirow[t]{3}{*}{ Lab } & \multicolumn{3}{|c|}{ Jory Managed } & \multicolumn{3}{|c|}{ Jory Unmanaged } & & \multirow{2}{*}{$\frac{\text { Miamian }}{2}$} & \multirow[b]{2}{*}{3} & \multirow[b]{2}{*}{1} & \multirow{2}{*}{$\frac{\text { Ottokee }}{2}$} & \multirow[b]{2}{*}{3} \\
\hline & 1 & 2 & 3 & 1 & 2 & 3 & 1 & & & & & \\
\hline & \multicolumn{12}{|c|}{ Variation of analytical replications $(n=2)$} \\
\hline 1 & 3 & 1 & 3 & 5 & 0 & 1 & 7 & 3 & 5 & 1 & 7 & 5 \\
\hline 2 & 1 & 0 & 7 & 1 & 0 & 7 & 3 & 1 & 12 & 1 & 3 & 0 \\
\hline \multirow[t]{2}{*}{3} & 0 & 0 & 2 & 7 & 2 & 19 & 9 & 3 & 10 & 2 & 12 & 4 \\
\hline & \multicolumn{12}{|c|}{ Variation of field replications $(n=3)$} \\
\hline 1 & & 3 & & & 20 & & & 7 & & & 34 & \\
\hline 2 & & 9 & & & 16 & & & 4 & & & 34 & \\
\hline 3 & & 5 & & & 13 & & & 60 & & & 26 & \\
\hline 4 & & 6 & & & 16 & & & 15 & & & 24 & \\
\hline
\end{tabular}



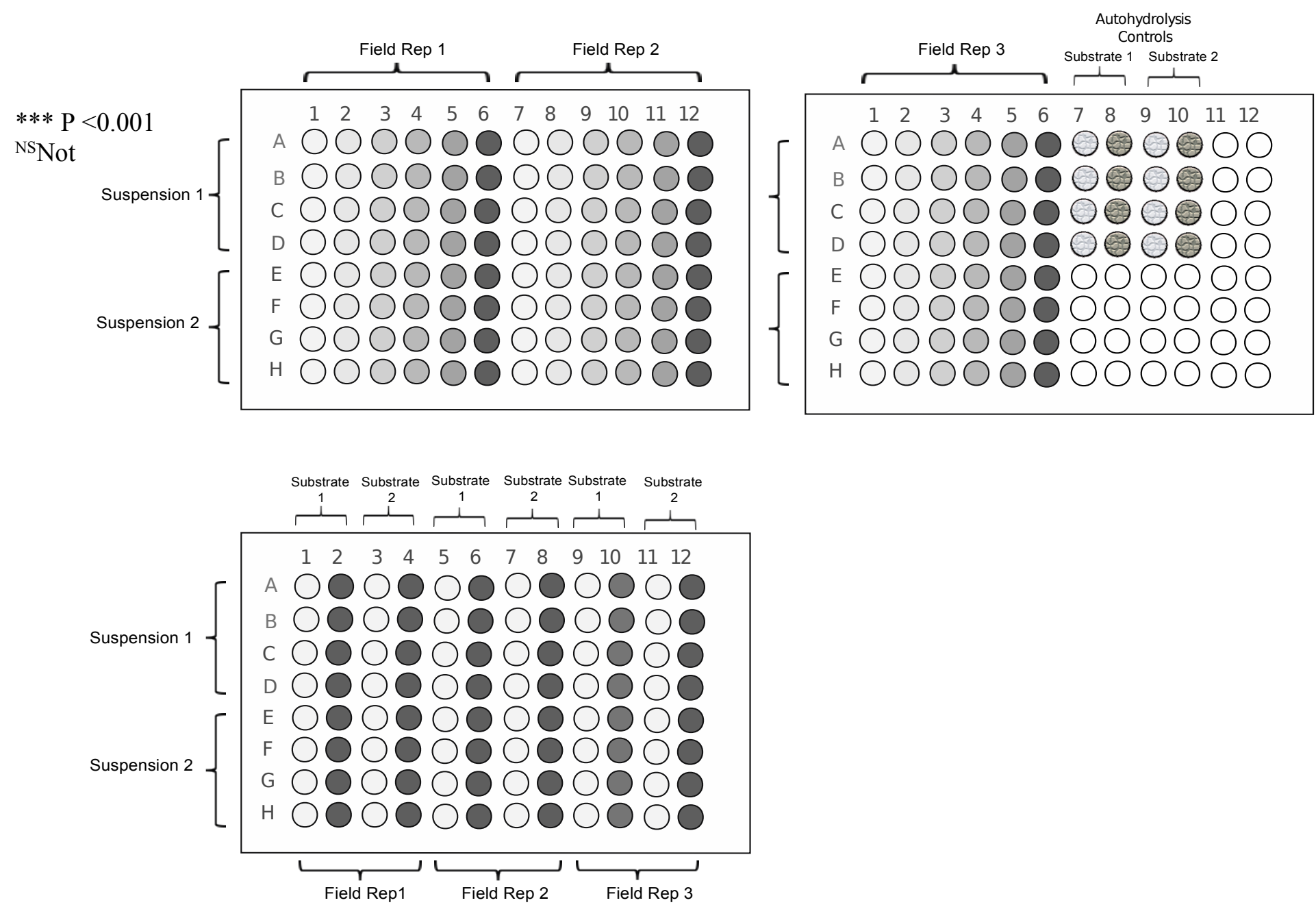

significant at $\mathrm{P}<0.05$

Figure 1. Microplate assay layouts. The bottom plate shows the layout for samples (light circles) and controls (dark circles) for one soil and two substrates, including three field replicates, two suspension 
replicates, with four microplate well replicates each (adapted from Deng et al., 2011). The top two plates consist of standards with increasing MUF concentration and autohydrolysis controls. 
Table 1. Description and properties of soils

\begin{tabular}{|c|c|c|c|c|c|c|c|}
\hline Soil & Vegetation & pH & Total C & Total N & Sand & Silt & Clay \\
\hline & & & \multicolumn{2}{|c|}{-----------g kg ${ }^{-1}$--------- } & \multicolumn{3}{|c|}{ 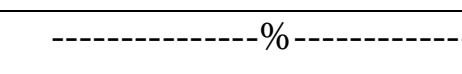 } \\
\hline $\begin{array}{l}\text { Jory silty clay loam (fine, mixed, } \\
\text { active mesic Xeric palehumult) }\end{array}$ & $\begin{array}{l}\text { Christmas trees } \\
\text { (managed) }\end{array}$ & 5.2 & 27.9 & 2.2 & 46 & 38 & 16 \\
\hline $\begin{array}{l}\text { Jory silty clay loam (fine, mixed, } \\
\text { active mesic Xeric palehumult) }\end{array}$ & $\begin{array}{l}\text { Douglas Fir } \\
\text { (unmanaged) }\end{array}$ & 6.0 & 36.8 & 2.7 & 52 & 34 & 14 \\
\hline $\begin{array}{l}\text { Miamian silt loam (fine, mixed, } \\
\text { active, mesic Oxyaquic Hapludalfs) }\end{array}$ & $\begin{array}{l}\text { Mixed grasses } \\
\text { (unmanaged) }\end{array}$ & 5.8 & 27.9 & 2.0 & 38 & 40 & 22 \\
\hline $\begin{array}{l}\text { Ottokee fine sand (mixed, mesic } \\
\text { Aquic Udipsamnents) }\end{array}$ & $\begin{array}{l}\text { Row cropped } \\
\text { (managed) }\end{array}$ & 7.3 & 17.6 & $\mathrm{ND} \dagger$ & 90 & 8 & 2 \\
\hline
\end{tabular}

†Not detectable. 
Table 2. Soil enzyme activities by bench or microplate methods across labs

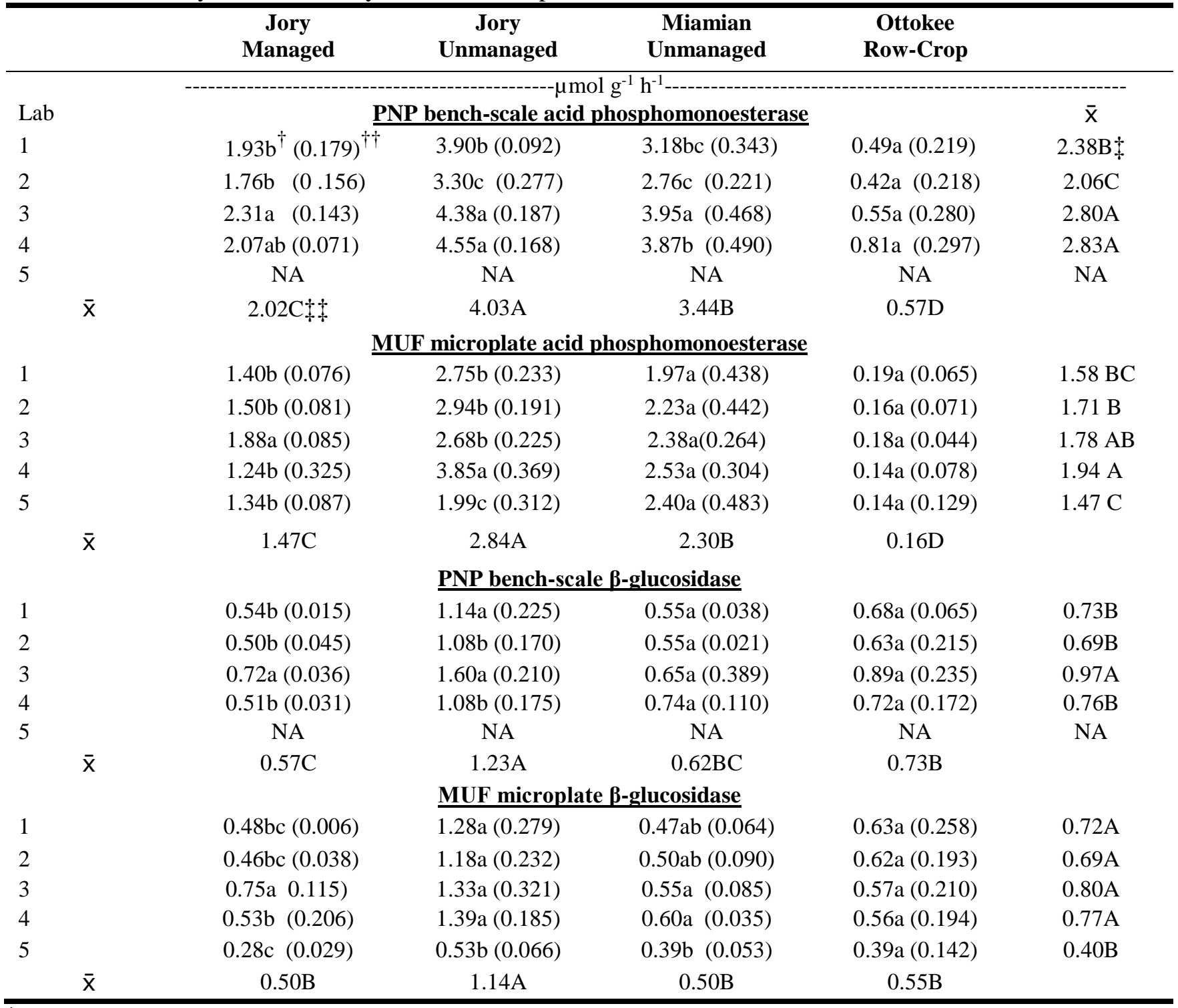

${ }^{\dagger}$ Values in a column within the same assay and soil type followed by the same lower case letter are not significantly different at $p=0.05$.

${ }^{\dagger \dagger}$ Values in parentheses are standard deviations.

${ }^{\ddagger}$ Values in the mean column within an assay followed by the same upper case letter are not significantly different at $p=0.05$

${ }^{\ddagger}$ Values in the mean row within an enzyme method followed by the same upper case letter are not significantly different at $p=0.05$. 
Table 3. Sources of variation (CV) for acid phosphatase activity using the MUF microplate method

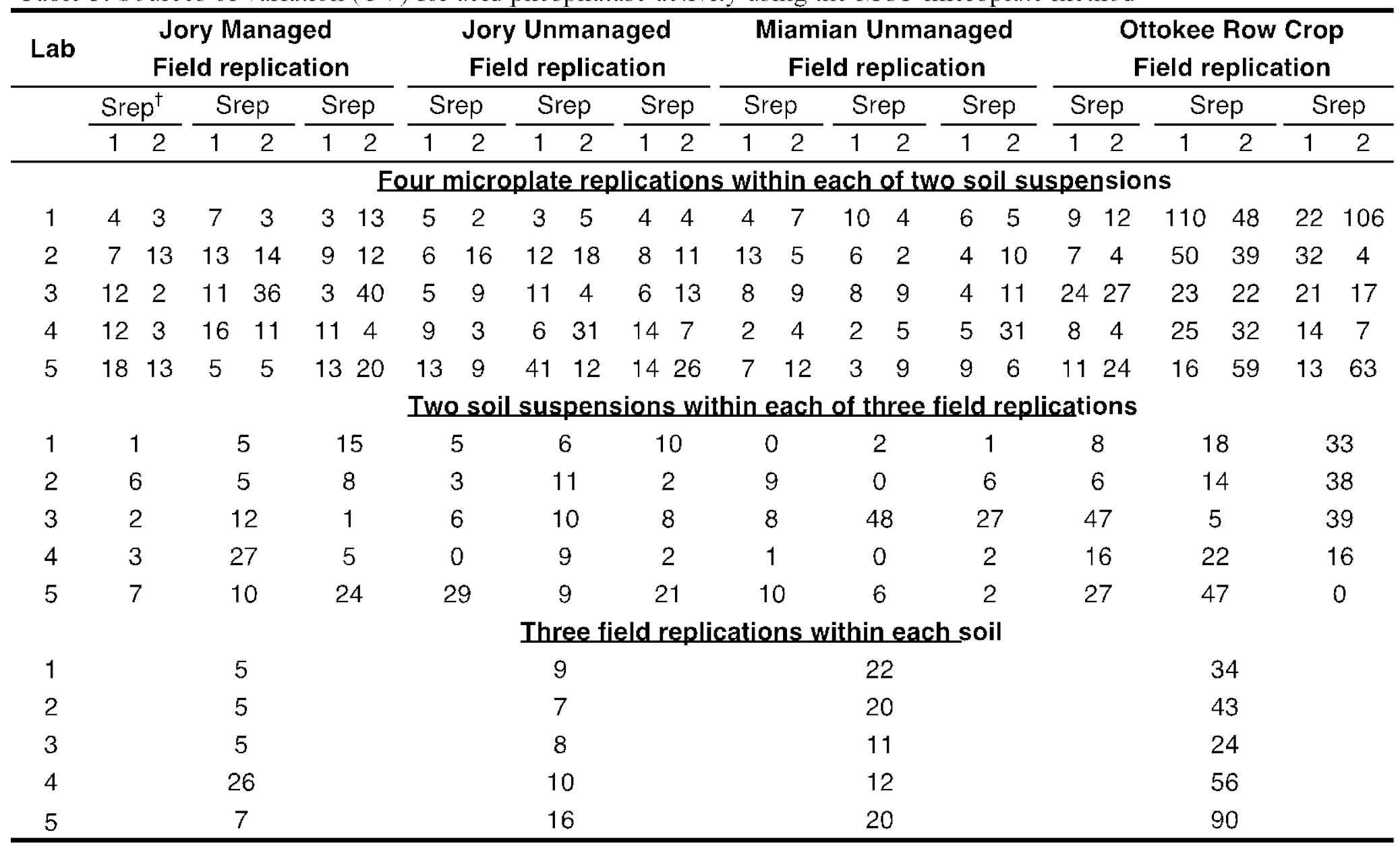

tSuspension replication. 
Table 4. Sources of variation (CV) for $\beta$-glucosidase activity using the MUF microplate method.

\begin{tabular}{|c|c|c|c|c|c|c|c|c|c|c|c|c|c|c|c|c|c|c|c|c|c|c|c|}
\hline \multirow[t]{3}{*}{ Lab } & \multicolumn{6}{|c|}{$\begin{array}{l}\text { Jory Managed } \\
\text { Field replication }\end{array}$} & \multicolumn{5}{|c|}{$\begin{array}{l}\text { Jory Unmanaged } \\
\text { Field replication }\end{array}$} & \multicolumn{6}{|c|}{$\begin{array}{l}\text { Miamian Unmanaged } \\
\text { Field replication }\end{array}$} & \multicolumn{6}{|c|}{$\begin{array}{c}\text { Ottokee Row Crop } \\
\text { Field replication }\end{array}$} \\
\hline & \multicolumn{2}{|c|}{ SRept } & \multicolumn{2}{|c|}{ SRep } & \multicolumn{2}{|c|}{ SRep } & \multicolumn{2}{|c|}{ SRep } & \multicolumn{2}{|c|}{ SRep } & SRep & \multicolumn{2}{|c|}{ SRep } & \multicolumn{2}{|c|}{ SRep } & \multicolumn{2}{|c|}{ SRep } & \multicolumn{2}{|c|}{ SRep } & \multicolumn{2}{|c|}{ SRep } & \multicolumn{2}{|c|}{ SRep } \\
\hline & 1 & 2 & 1 & 2 & 1 & 2 & 1 & 2 & 1 & 2 & 12 & 1 & 2 & 1 & 2 & 1 & 2 & 1 & 2 & 1 & 2 & 1 & 2 \\
\hline & & & \multicolumn{21}{|c|}{ Microplate assay replications $(n=4)$ within a soil suspension } \\
\hline 1 & 8 & 8 & 4 & 7 & 17 & 4 & 4 & 6 & 8 & 11 & 1917 & 7 & 11 & 9 & 15 & 10 & 4 & 13 & 48 & 22 & 26 & 24 & 36 \\
\hline 2 & 17 & 14 & 15 & 14 & 6 & 17 & 7 & 8 & 5 & 10 & 910 & 22 & 18 & 4 & 21 & 9 & 14 & 12 & 20 & 38 & 118 & 19 & 13 \\
\hline 3 & 9 & 22 & 13 & 36 & 23 & 22 & 12 & 7 & 10 & 20 & 189 & 17 & 70 & 11 & 15 & 20 & 39 & 36 & 69 & 22 & 26 & 22 & 21 \\
\hline 4 & 21 & 16 & 6 & 6 & 14 & 42 & 18 & 9 & 13 & 6 & 2438 & 17 & 14 & 9 & 9 & 9 & 10 & 6 & 11 & 11 & 30 & 10 & 9 \\
\hline \multirow[t]{2}{*}{5} & 22 & 30 & 23 & 4 & 17 & 10 & 24 & 7 & 18 & 18 & 1014 & 19 & 7 & 5 & 22 & 10 & 35 & 36 & 16 & 8 & 16 & 38 & 22 \\
\hline & \multicolumn{23}{|c|}{ Soil suspension replications $(n=2)$} \\
\hline 1 & $\theta$ & 6 & & 5 & 4 & 4 & & 2 & 9 & & 9 & 3 & 3 & 1 & & 1 & 1 & & 13 & c & 0 & & 0 \\
\hline 2 & g & 9 & & 2 & 1 & 6 & & 4 & 10 & & 7 & 1 & 0 & 1 & & 2 & 2 & & 3 & 1 & 15 & & 9 \\
\hline 3 & 1 & 3 & & 0 & 3 & 3 & & 2 & 4 & & 28 & 1 & & 4 & & 13 & 3 & & 32 & 1 & 17 & & 21 \\
\hline 4 & 4 & 4 & & 1 & 1 & 3 & & 14 & 7 & & 1 & 5 & 5 & 9 & & 4 & 4 & & 5 & $\varsigma$ & 9 & & 7 \\
\hline \multirow[t]{2}{*}{5} & 3 & 3 & & 3 & 3 & 3 & & 13 & 1 & & 26 & 2 & 2 & 1 & & & 8 & & 1 & 2 & 20 & & 20 \\
\hline & \multicolumn{23}{|c|}{ Field replications $(n=3)$} \\
\hline 1 & \multicolumn{6}{|c|}{1} & \multicolumn{5}{|c|}{22} & \multicolumn{6}{|c|}{14} & \multicolumn{6}{|c|}{41} \\
\hline 2 & \multicolumn{6}{|c|}{8} & & & 20 & & & & & 18 & & & & & & & 31 & & \\
\hline 3 & & & 1 & 5 & & & & & 24 & & & & & 1 & & & & & & & 37 & & \\
\hline 4 & & & 3 & 9 & & & & & 13 & & & & & 6 & & & & & & & 35 & & \\
\hline 5 & & & 1 & 0 & & & & & 12 & & & & & 1. & & & & & & & 37 & & \\
\hline
\end{tabular}

Suspension replication 
Table 5. Sources of variation (CV) for acid phosphatase activity using the bench method (Lab \#4 did not replicate the bench method, and Lab $\# 5$ did not perform the bench-scale assay).

\begin{tabular}{|c|c|c|c|c|c|c|c|c|c|c|c|c|c|}
\hline \multirow[t]{2}{*}{ Lab } & \multicolumn{3}{|c|}{ Jory Managed } & \multicolumn{3}{|c|}{ Jory Unmanaged } & \multicolumn{3}{|c|}{ Miamian } & \multicolumn{3}{|c|}{ Ottokee } & \multirow[t]{2}{*}{ Mean CV } \\
\hline & 1 & 2 & 3 & 1 & 2 & 3 & 1 & 2 & 3 & 1 & 2 & 3 & \\
\hline \multicolumn{14}{|c|}{ Assay replications $(n=2)$} \\
\hline 1 & 3 & 4 & 2 & 2 & 2 & 2 & 2 & 3 & 0 & 13 & 2 & 8 & 3 \\
\hline 2 & 1 & 1 & 0 & 3 & 4 & 16 & 2 & 2 & 4 & 3 & 3 & 8 & 4 \\
\hline 3 & 1 & 2 & 7 & 7 & 7 & 6 & 2 & 1 & 1 & 0 & 13 & 14 & 5 \\
\hline \multicolumn{14}{|c|}{ Field replications $(n=3)$} \\
\hline 1 & & 9 & & & 2 & & & 11 & & & 45 & & 17 \\
\hline 2 & & 9 & & & 8 & & & 8 & & & 52 & & 19 \\
\hline 3 & & 6 & & & 4 & & & 12 & & & 51 & & 18 \\
\hline 4 & & 3 & & & 4 & & & 13 & & & 37 & & 14 \\
\hline
\end{tabular}

Table 6. Sources of variation (CV) for $\beta$-glucosidase activity using the bench method (Lab \#4 did not replicate the bench method, \#5 did not perform the bench-scale assay).

\begin{tabular}{|c|c|c|c|c|c|c|c|c|c|c|c|c|c|}
\hline \multirow[t]{2}{*}{ Lab } & \multicolumn{3}{|c|}{ Jory Managed } & \multicolumn{3}{|c|}{ Jory Unmanaged } & \multicolumn{3}{|c|}{ Miamian } & \multicolumn{3}{|c|}{ Ottokee } & \multirow[t]{2}{*}{ Mean CV } \\
\hline & 1 & 2 & 3 & 1 & 2 & 3 & 1 & 2 & 3 & 1 & 2 & 3 & \\
\hline \multicolumn{14}{|c|}{ Assay replications $(n=2)$} \\
\hline 1 & 3 & 1 & 3 & 5 & 0 & 1 & 7 & 3 & 5 & 1 & 7 & 5 & 3 \\
\hline 2 & 1 & 0 & 7 & 1 & 0 & 7 & 3 & 1 & 12 & 1 & 3 & 0 & 3 \\
\hline 3 & 0 & 0 & 2 & 7 & 2 & 19 & 9 & 3 & 10 & 2 & 12 & 4 & 6 \\
\hline \multicolumn{14}{|c|}{ Field replications $(n=3)$} \\
\hline 1 & & 3 & & & 20 & & & 7 & & & 34 & & 16 \\
\hline 2 & & 9 & & & 16 & & & 4 & & & 34 & & 16 \\
\hline 3 & & 5 & & & 13 & & & 60 & & & 26 & & 26 \\
\hline 4 & & 6 & & & 16 & & & 15 & & & 24 & & 15 \\
\hline
\end{tabular}


Table 7. Pearson's correlation coefficients (r values) for linear correlation between enzyme activities and biomass of microbial groups based on ester linked fatty acids (EL FAME) $(n=24)$.

\begin{tabular}{|c|c|c|c|c|}
\hline \multirow{2}{*}{ Microbial Functional Group } & \multicolumn{2}{|c|}{ Acid Phosphomonoesterase } & \multicolumn{2}{|c|}{$\beta$-Glucosidase } \\
\hline & MUF Microplate & PNP Bench-scale & MUF Microplate & PNP Bench-scale \\
\hline
\end{tabular}

\begin{tabular}{lllll} 
Arbuscular mycorrhizal fungi & $0.64 * * *$ & $0.69 * * *$ & $0.19^{\mathrm{NS}}$ & $0.12^{\mathrm{NS}}$ \\
Actinobacteria & $0.78^{* * *}$ & $0.75^{* * *}$ & $0.76^{* * *}$ & $0.70^{* * *}$ \\
Gram-negative bacteria & $0.80^{* * *}$ & $0.81^{* * *}$ & $0.89^{* * *}$ & $0.85^{* * *}$ \\
Gram-positive bacteria & $0.74 * * *$ & $0.71^{* * *}$ & $0.80^{* * *}$ & $0.75^{* * *}$ \\
Total bacteria & $0.77^{* * *}$ & $0.76^{* * *}$ & $0.84^{* * *}$ & $0.79^{* * *}$ \\
Total fungi & $0.81^{* * *}$ & $0.83^{* * *}$ & $0.83^{* * *}$ & $0.76^{* * *}$ \\
\hline
\end{tabular}

$* * * \mathrm{P}<0.001$

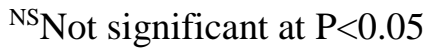



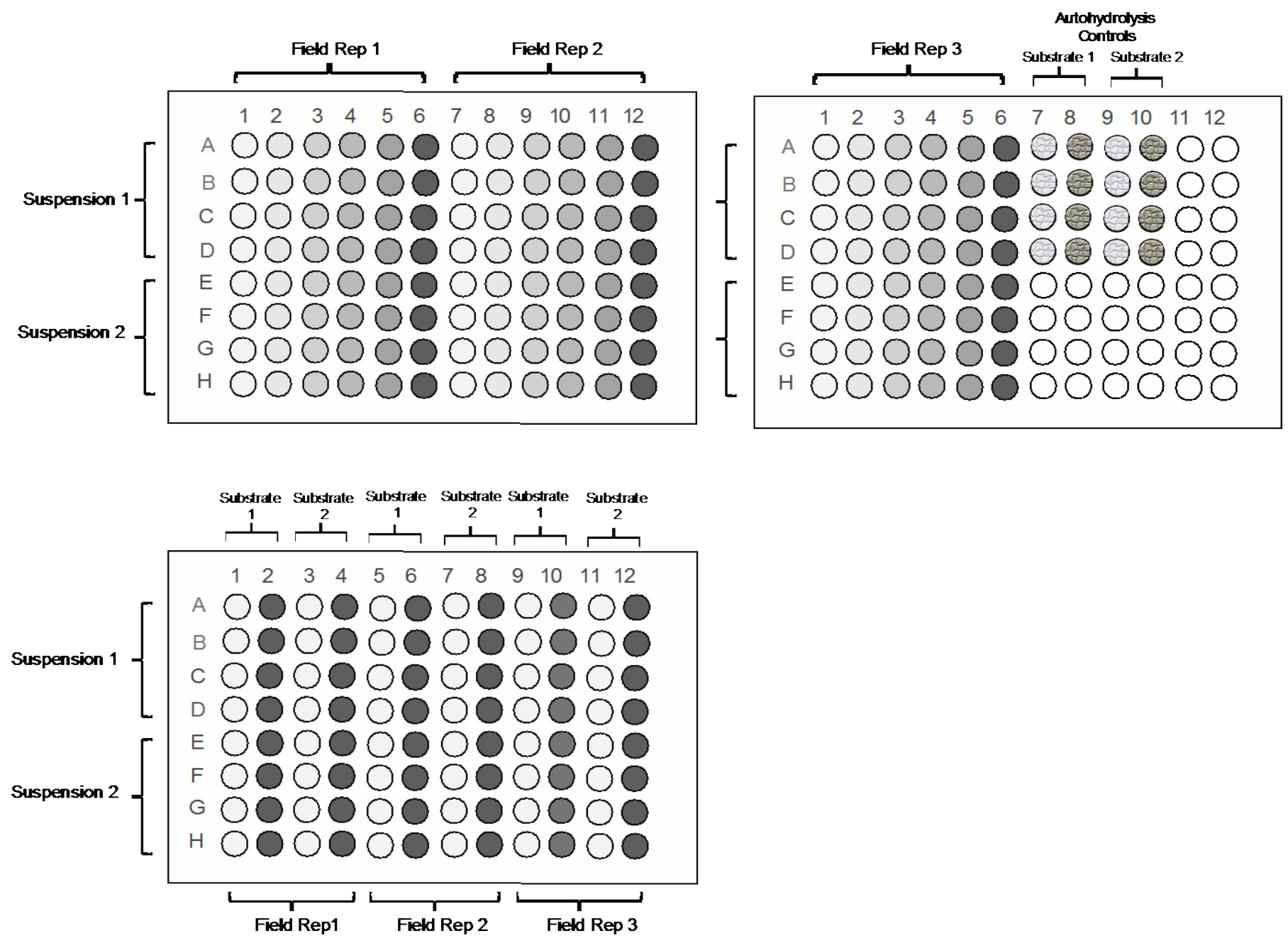

Figure 1. Microplate assay layouts. The bottom plate shows the layout for samples (light circles) and controls (dark circles) for one soil and two substrates, including three field replicates, two suspension replicates, with four microplate well replicates each (adapted from Deng et al., 2011). The top two plates consist of standards with increasing MUF concentration and autohydrolysis controls. 


\section{MICROPLATE FLUORIMETRIC ASSAY OF SOIL ENZYMES PROCEDURES}

\section{INTRODUCTION}

Use of the microplate format in soil enzyme assays offers the advantage of simultaneous analysis of multiple enzymes using a small quantity of soil. A microplate reader can simultaneously, measure many samples (e.g., in 96 wells) for absorbance or fluorescence in microliter volumes, which allows researchers to substantially reduce reagent costs and possibly assay time over conventional bench-scale assays.

Enzyme activity assays using the microplate fluorescence methodology are gaining greater interest, in part, owing to the high sensitivity of fluorescence detection and significantly less susceptibility to turbidity interference, compared to absorption based detection (Deng et al., 2013). A major concern for fluorescence-based methods is the significant quenching of fluorescence of compounds such as 4-methylumbelliferyl (MUF) in soil, which varies temporally and spatially (Freeman et al., 1995). Fluorescence is also affected by $\mathrm{pH}$ and temperature (Lakowicz, 1983). The relative florescence signals of MUF are highest between $\mathrm{pH} 10$ and 11, which could be $>35,000$-fold of those detected at $\mathrm{pH} 6.0$ (Deng et al., 2013). As temperature increases, fluorescence decreases due to an increase in molecular motion that results in more frequent molecular collisions and subsequent loss of energy (Guilbault, 1990). Consequently, quantification of MUF in soil requires a calibration curve for each soil. For quantitative detection, it is also important to treat standards, blanks, and samples in exactly the same manner, prepare all solutions using the same reagents and preparation techniques, and measure at the same temperature after the same amount of time. The additional precautions and calibration steps add considerable labor and expense to the assay as well as additional sources of error.

Using the assay protocols described in Deng et al. (2011) that evolved from earlier studies (Drouillon and Merckx, 2005; Marx et al., 2001), several recent studies have shown comparable results between MUF-microplate and $\rho$-nitrophenol-bench scale assay approaches (Deng et al., 2013; Dick et al., 2013). Although uniformity of diluted soil suspensions is a potential concern for the MUF microplate method, Dick et al. (2013) found that taking samples from the top, middle, or bottom of the suspension had no significant effect $(p=0.49)$ on variability or detecting treatment effects on enzyme activity. Furthermore, sonication of the suspension prior to sampling did not improve reproducibility of the MUF microplate method.

In recent years there have been a growing number of published papers attempting to mimic in situ $\mathrm{pH}$ or temperature. This may be appropriate depending on the goals of the research but such results need to be interpreted with caution. First because these less than optimal conditions can reduce the activity; this could obscure treatment effects or even change the ranking of treatment effects on soil enzyme activities. Secondly, other aspects of the assay such as saturating the enzyme with substrate (orders of magnitude, use of cofactors, and that soil is in slurry solution - all makes for very different conditions compared to in situ condition. The method described here is based on optimal conditions.

\section{PRINCIPLES}

The assay described below is based on detection of MUF released by enzymatic hydrolysis of specific substrates when incubated with soil at the optimal $\mathrm{pH}$ of the assayed 
enzyme. Following incubation for a defined time at the desired temperature, MUF is quantified upon addition of THAM (0.1 M, pH 10) as reported by Deng et al. (2013). Concentrations of MUF are calculated using a calibration curve and enzyme activities are expressed as mmole or $\mu$ mole MUF released $\mathrm{kg}^{-1}$ soil $\mathrm{h}^{-1}$.

\section{ENZYME ASSAYS PROTOCOL}

Apparatus

- 1-L beaker

- 1-L volumetric flasks

- 100-mL volumetric flasks

- 150-mL beakers

- Stir plate capable of regulating to $600 \mathrm{rpm}$

- 3.75-cm magnetic stir bar

- Multichannel pipette $(0-250 \mu \mathrm{L})$

- Black solid polystyrene microplates, 96-well (CLS3915; Costar microplates; Corning, Inc., Lowell, MA).

- Incubator $\left(37^{\circ} \mathrm{C}\right)$

- Fluorescence microplate reader (360-nm excitation; 460-nm emission)

Reagents (Table 1)

- Modified universal buffer (MUB) stock solution: Dissolve $12.1 \mathrm{~g}$ tris (hydroxymethyl) aminomethane (THAM), $11.6 \mathrm{~g}$ maleic acid, $14.0 \mathrm{~g}$ citric acid, and $6.3 \mathrm{~g}$ boric acid in 800 $\mathrm{mL} 0.5 \mathrm{M} \mathrm{NaOH}$. Adjust to $1 \mathrm{~L}$ with $0.5 \mathrm{M} \mathrm{NaOH}$ and store at $4^{\circ} \mathrm{C}$.

- MUB working solution (pH 6.0): Place $200 \mathrm{~mL}$ MUB stock solution in 1-L beaker containing magnetic stir bar. Place on stir plate and titrate the $\mathrm{pH}$ with $\mathrm{HCl}$ while stirring. Adjust the volume to $1 \mathrm{~L}$ with DI water.

- Methylumbelliferyl substrates $(2 \mathrm{mM})$ : Weigh $0.068 \mathrm{~g}$ methylumbelliferyl- $\beta$-Dglucoside (MUF-G; Sigma Aldrich M3633) or 0.052 g methylumbelliferyl-phosphate (MUF-P; Sigma Aldrich M8883) into a 100-mL volumetric flask and adjust the volume to $100 \mathrm{~mL}$ with DI water. Prepare the solutions daily or aliquot and store for no more than two weeks at $-20^{\circ} \mathrm{C}$. Thaw one aliquot on the day of use and discard leftovers.

- $\operatorname{THAM}$ (0.1 M, pH 10): Dissolve $12.1 \mathrm{~g}$ Tris (hydroxymethyl) aminomethane (THAM) (MW 121.14) in $700 \mathrm{~mL}$ DI water. Adjust $\mathrm{pH}$ to 10.0 with $0.1 \mathrm{M} \mathrm{NaOH}$, and then adjust volume to $1 \mathrm{~L}$ with DI water. Store in plastic container at room temperature.

- Methylumbelliferone (MUF) stock solution (100 $\mu \mathrm{M})$ : Dissolve $0.0202 \mathrm{~g}$ 4methylumbelliferone sodium salt (98\%; M1508; Sigma Aldrich) in $700 \mathrm{~mL}$ DI water, then adjust volume to $1 \mathrm{~L}$. Store in the dark at $4^{\circ} \mathrm{C}$ for no more than 2 weeks or in aliquots at $-20^{\circ} \mathrm{C}$ for no more than one month for this study. Thaw one aliquot on the day of use and discard leftovers.

- MUF working standards: 0, 5, 10, 20, 30, and $50 \mu \mathrm{M}$ MUF standards are prepared by diluting $0,5,10,20,30$, or $50 \mathrm{~mL}$ of the MUF stock solution $(100 \mu \mathrm{M})$ to $100 \mathrm{~mL}$ with DI water in $100 \mathrm{~mL}$ volumetric flasks. Store in the dark at $4^{\circ} \mathrm{C}$ for no more than 2 weeks.

Procedure (See Figure 1 for plate layout) 
1. Warm reagents in the incubator at assay temperature for $\sim 30 \mathrm{~min}$ prior to initiating the assay. Normally $37^{\circ} \mathrm{C}$ is used unless otherwise recommended in the original method development paper for a given assay.

2. Two replicate soil suspensions are prepared for each soil sample by weighing $1 \mathrm{~g}$ of soil into a $150 \mathrm{~mL}$ beaker, and adding $120 \mathrm{~mL}$ of DI water. The soil is homogenized for 30 min. using a $3.75 \mathrm{~cm}$ stir bar on a stir plate at $600 \mathrm{rpm}$.

3. A multichannel pipette with four tips is used, with continuous stirring, to load $100 \mu \mathrm{L}$ of suspension into each microplate well containing $50 \mu \mathrm{L}$ MUB pH 6.0. The same stir plate and speed should be used to carry out this step.

4. Add $50 \mu \mathrm{L}$ of MUF substrate to each well, mix by pipetting up and down several times, and incubate at $37^{\circ} \mathrm{C}$ for $1 \mathrm{~h}$.

a. The plates should be incubated in a shallow water bath in a pan that can be covered during incubation (can use aluminum foil). Make sure the water has reached $37^{\circ} \mathrm{C}$ prior to placing sample plates for incubation.

b. Substrate should be added to a plate as rapidly as possible but still with care taken in pipetting.

c. Make sure each plate is incubated for exactly $1 \mathrm{~h}$.

5. Following incubation, add $50 \mu \mathrm{L}$ of $0.1 \mathrm{M} \mathrm{THAM}$ (pH 10) to each well (in the same order as the substrate solution was added to keep the incubation time relatively consistent among samples) to terminate the reaction and increase fluorescence signal for its detection at $360 \mathrm{~nm}$ excitation and $460 \mathrm{~nm}$ emission. The relative fluorescence signal is stable under the stated conditions for several hours, with no detectable differences observed when readings were taken within three hour following the addition of THAM (Deng et al. 2013).

6. Four controls are performed in the same way except substrate is added after incubation. Controls are soil-specific.

7. Controls for autohydrolysis are prepared as for sample except DI water replaces soil suspension and substrate is added either before incubation or after the reaction is terminated by alkalization. These control will only need to be done once for each substrate.

8. Standards for soil-specific calibration curves are developed at the same time samples are assayed using the same soil suspension and procedure, except MUF standards are used in the place of MUF substrates. Briefly, $50 \mu \mathrm{L}$ of each MUF working standard solution are placed into microplate wells that each contains $50 \mu \mathrm{L}$ of MUB, followed by the addition of $100 \mu \mathrm{L}$ of soil suspension. After incubation, $50 \mu \mathrm{L}$ of THAM (pH 10) is added to each well as done for enzyme assays described above. The total volume in each well is $250 \mu \mathrm{L}$ and contains MUF standards of 0,250,500,1000,1500, or 2500 pmol. Average data obtained from both soil suspensions are used to develop a calibration curve for the tested soil.

9. Set microplate reader sensitivity for sample plate according to the highest standard on the standard plate (Table 2).

10. Calculations (see Deng et al. 2011 for more details):

- The average reading from the zero MUF standard should be subtracted from all other standard readings

- The intercept of the calibration curve should be forced through zero. 
- The average autohydrolysis is calculated by subtracting the average RFU of the autohydrolysis wells incubated with substrate added after reaction termination/alkalization from the average of the wells with substrate added before incubation.

Corrected fluorescence $\left(F_{\text {corrected }}\right)=\left(F_{\text {sample }}-F_{\text {avg control }}-F_{\text {avg autohydrolysis }}\right)$

In each sample assay well,

pmol MUF released $=\frac{\text { Fcorrected }}{\text { Slope of the MUF calibration curve }}$

Enzyme activity in soil, nmole MUF g-1 soil h$^{-1}\left(\equiv \mu\right.$ mole MUF kg${ }^{-1}$ soil h$\left.^{-1}\right)$

$=\frac{\text { pmol MUF released }}{100 \mu l \text { soil suspension }} \times \frac{1000 \mu l}{1 \mathrm{~mL}} \times \frac{120 \mathrm{~mL}}{1 \mathrm{~g} \mathrm{soil}} \times \frac{1 \mathrm{nmol}}{1000 \mathrm{pmol}} \times \frac{1}{1 \mathrm{~h}}$

\section{COMMENTS}

Pipetting is the most critical procedure for causing error in the MUF microplate method because of the small volumes that are used. In particular, retrieving sample volumes from the soil suspension is a critical pipetting step. To obtain accurate and reproducible data, it is important to check the pipette tips to ensure that the tips are tight and the multichannel pipette is calibrated and working properly. Also, caution should be exercised during pipetting to avoid trapping of air bubbles.

A fundamentally intractable issue with microplate assays is the variation in fluorescence over time of MUF standard's. Our experience has been that this is particularly acute with long term storage and reuse of MUF stock where the fluorescence is not stable over time.

We emphasize that the optimum $\mathrm{pH}$ be used and the optimal value chosen be based on $\mathrm{pH}$ curves found in the literature for a given enzyme. The most comprehensive compilation of soil enzyme assays is in Dick (2011) where optimal pHs are reported for methods that have been vetted. If this has not been done for an enzyme of interest, preliminary $\mathrm{pH}$ curve investigation should be done to determine the $\mathrm{pH}$ optima.

The above protocol is standardizing the operationally defined protocols $(37 \mathrm{C}$ incubation temperature, $\mathrm{pH} 10$ THAM buffer to kill reaction, 1 hour incubation, controlling for quenching in the standard curve and autohydrolysis, fluorescence reading within 1 hour of stopping the enzyme reaction, pre-warming incubation reagents, and method of developing soil suspension) to enable cross paper and meta analyses. Since $\mathrm{pH}$ optima currently is based on PNP bench scale methods which did not use fluorescing substrates, further studies may show a different $\mathrm{pH}$ optima with MUF microplate for a given enzyme.

If an alternative methodology is used to attempt to mimic some aspect of in situ conditions, data should also be generated using the standardized approach to allow cross paper comparison and enable firm conclusions and interpretation of the data. 


\section{REFERENCES}

Deng S., Kang H., Freeman, C., 2011. Microplate fluorimetric assay of soil enzymes. In: Dick, R.P. (Ed.), Methods of Soil Enzymology, Vol 9. Soil Science Society of America, Madison, WI, pp. 311-318.

Deng, S., Popova, I.E., Dick, L., Dick, R., 2013. Bench scale and microplate format assay of soil enzyme activities using spectroscopic and fluorometric approaches. Applied Soil Ecology 64, 84-90.

Dick, R.P. (ed). 2011. Methods of Soil Enzymology. Soil Science Society of America, Madison Wisconsin.

Dick, L.K., Jia, G., Deng, S., Dick, R.P., 2013. Evaluation of microplate and bench-scale $\beta$ glucosidase assays for reproducibility, comparability, kinetics, and homogenization methods in two soils. Biology and Fertility of Soils 49, 1227-1236.

Freeman, C., Liska, G.P, Ostle, N.H., Jones, S.E., Lock, M.A., 1995. The use of fluorogenic substrates for measuring enzyme activity in peatlands. Plant Soil 175, 147-152.

Guilbault, G.G., 1990. Practical Fluorescence, Second Edition, Marcel Dekker, Inc., New.

Lakowicz, J.R., 1983. Principles of Fluorescence Spectroscopy. Plenum Press, New York. 

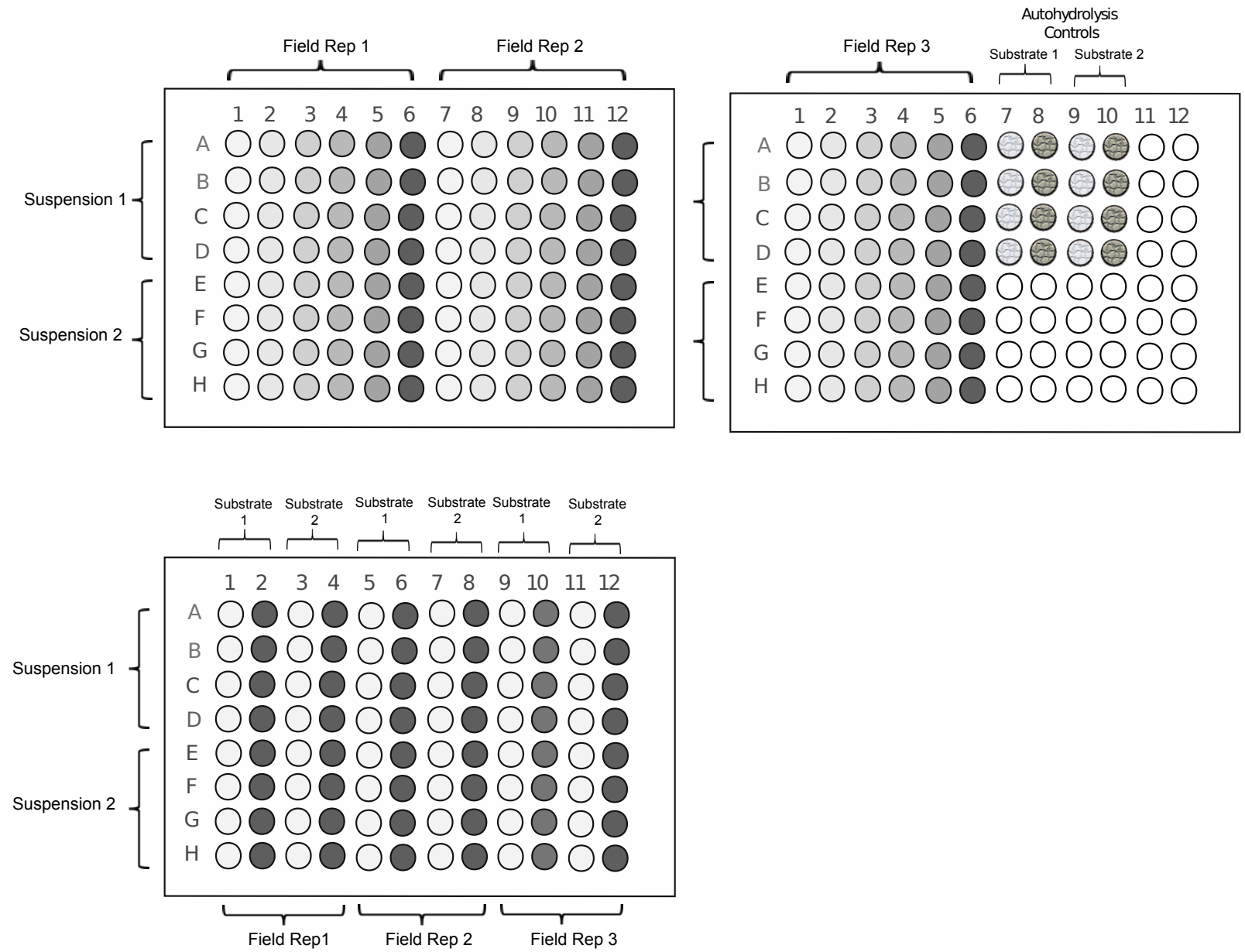

Figure 1. Plate layouts for assaying activities of two enzymes in four soils. The plates above represent requirements for one soil and two substrates, including three field replications, two soil suspension replications and four analytical replications. The top two plates consist of standards with increasing MUF concentration and autohydrolysis controls. The bottom plates show layout for samples (light circles) and controls (dark circles). 
Table 1. Suggested source of substrates

\begin{tabular}{ll} 
Sigma Catalog \# & Substrate/Standard \\
\hline M3633 & 4-Methylumbelliferyl $\beta$-D-glucopyranoside \\
M8883 & 4-Methylumbelliferyl phosphate \\
M1508 & 4-Methylumbelliferone sodium salt \\
N7006 & 4-Nitrophenyl $\beta$-D-glucopyranoside \\
P4744 & Phosphatase substrate \\
1048 & 4-Nitrophenol \\
T6066 & Tris base (THAM: MW 121.14) \\
\hline
\end{tabular}

Table 2. Microplate reader and gain settings

\begin{tabular}{ccc}
$\begin{array}{c}\text { Microplate } \\
\text { Reader } \\
\text { (brand/model) }\end{array}$ & $\begin{array}{c}\text { Does } \\
\text { Reader } \\
\text { have Auto- } \\
\text { Sensitivity } \\
\text { Setting? }\end{array}$ & Determination of Gain Setting (sensitivity) \\
\hline $\begin{array}{c}\text { BioTek } \\
\text { Synergy H1 }\end{array}$ & Yes & $\begin{array}{c}\text { Set auto-sensitivity to highest well of calibration plate, then } \\
\text { apply same value to sample plates }\end{array}$ \\
\hline
\end{tabular}

